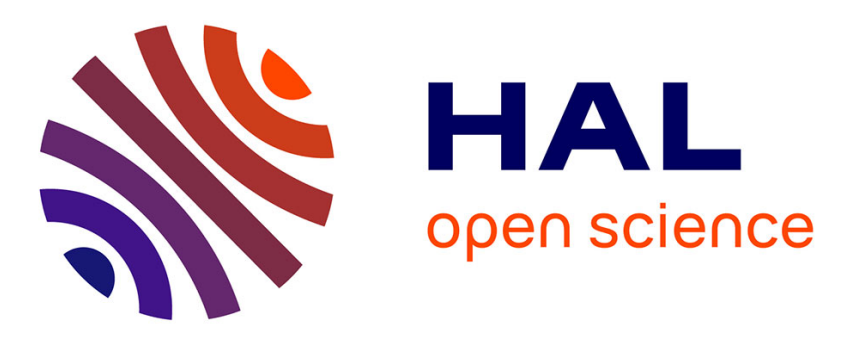

\title{
Influence of Calcium Perchlorate on the Search for Organics on Mars with Tetramethylammonium Hydroxide Thermochemolysis
}

\author{
Yuanyuan He, Arnaud Buch, Cyril Szopa, Amy J. Williams, Maeva Millan, \\ Charles A. Malespin, Daniel P. Glavin, Caroline Freissinet, Jennifer L. \\ Eigenbrode, Samuel Teinturier, et al.
}

\section{To cite this version:}

Yuanyuan He, Arnaud Buch, Cyril Szopa, Amy J. Williams, Maeva Millan, et al.. Influence of Calcium Perchlorate on the Search for Organics on Mars with Tetramethylammonium Hydroxide Thermochemolysis. Astrobiology, 2021, 21 (3), pp.279-297. 10.1089/ast.2020.2252 . insu-03070253

\section{HAL Id: insu-03070253 \\ https://hal-insu.archives-ouvertes.fr/insu-03070253}

Submitted on 14 Oct 2021

HAL is a multi-disciplinary open access archive for the deposit and dissemination of scientific research documents, whether they are published or not. The documents may come from teaching and research institutions in France or abroad, or from public or private research centers.
L'archive ouverte pluridisciplinaire HAL, est destinée au dépôt et à la diffusion de documents scientifiques de niveau recherche, publiés ou non, émanant des établissements d'enseignement et de recherche français ou étrangers, des laboratoires publics ou privés. 


\title{
Influence of Calcium Perchlorate on the Search for Organics on Mars with Tetramethylammonium Hydroxide Thermochemolysis
}

\author{
Yuanyuan He, Arnaud Buch,, Cyril Szopa, ${ }^{2}$ Amy J. Williams, ${ }^{3,4}$ Maëva Millan, ${ }^{3,5}$ Charles A. Malespin, ${ }^{3}$ \\ Daniel P. Glavin, ${ }^{3}$ Caroline Freissinet, ${ }^{2}$ Jennifer L. Eigenbrode, ${ }^{3}$ Samuel Teinturier, ${ }^{3}$ David Coscia, ${ }^{2}$ \\ Jean-Yves Bonnet, ${ }^{2,6}$ Jennifer C. Stern, ${ }^{3}$ Fabien Stalport, ${ }^{7}$ Melissa Guzman, ${ }^{2}$ \\ Naila Chaouche-Mechidal, ${ }^{7}$ Pin Lu, ${ }^{8}$ Rafael Navarro-Gonzalez, ${ }^{9}$ Vincent Butin, ${ }^{1}$ Jamila El Bekri, \\ Hervé Cottin, ${ }^{7}$ Sarah Johnson, ${ }^{5}$ Michel Cabane, ${ }^{2}$ and Paul R. Mahaffy ${ }^{3}$
}

\begin{abstract}
The Mars Organic Molecule Analyzer (MOMA) and Sample Analysis at Mars (SAM) instruments onboard the Exomars 2022 and Mars Science Laboratory rovers, respectively, are capable of organic matter detection and differentiating potentially biogenic from abiotic organics in martian samples. To identify organics, both these instruments utilize pyrolysis-gas chromatography coupled to mass spectrometry, and the thermochemolysis agent tetramethylammonium hydroxide (TMAH) is also used to increase organic volatility. However, the reactivity and efficiency of TMAH thermochemolysis are affected by the presence of calcium perchlorate on the martian surface. In this study, we determined the products of TMAH pyrolysis in the presence and absence of calcium perchlorate at different heating rates (flash pyrolysis and SAM-like ramp pyrolysis with a $35^{\circ} \mathrm{C} \cdot \mathrm{min}^{-1}$ heating rate). The decomposition mechanism of TMAH pyrolysis in the presence of calcium perchlorate was studied by using stepped pyrolysis. Moreover, the effect of calcium perchlorate (at Mars-relevant concentrations) on the recovery rate of fatty acids with TMAH thermochemolysis was studied. Results demonstrate that flash pyrolysis yields more diversity and greater abundances of TMAH thermochemolysis products than does the SAM-like ramp pyrolysis method. There is no obvious effect of calcium perchlorate on TMAH degradation when the $\left[\mathrm{ClO}_{4}^{-}\right]$is lower than 10 weight percent (wt \%). Most importantly, the presence of calcium perchlorate does not significantly impact the recovery rate of fatty acids with TMAH thermochemolysis under laboratory conditions, which is promising for the detection of fatty acids via TMAH thermochemolysis with the SAM and MOMA instruments on Mars. Key Words: Calcium perchlorate-TMAH thermochemolysis-Pyrolysis-GCMS-Mars-SAM and MOMA. Astrobiology 21, xxx-xxx.
\end{abstract}

\section{Introduction}

$\mathbf{N}$ ASA's 2008 PHOENIx Mars lander and its wet chemistry laboratory (WCL) was the first experiment on Mars, which detected $\sim 0.4-0.6$ weight percent (wt \%) $\mathrm{ClO}_{4}^{-}$ions in the martian soil (Hecht et al., 2009). After this initial in situ detection, calcium and magnesium perchlorates were identified at the landing site (Hecht et al., 2009), and Kounaves et al. (2014b) concluded that the soil samples analyzed by the Phoenix's WCL could be composed of an $\sim 3: 2$ ratio of

\footnotetext{
${ }^{1}$ Laboratoire Génie des Procédés et Matériaux (LGPM), CentraleSupélec, University Paris-Saclay, Gif-sur-Yvette, France.

${ }^{2}$ LATMOS/IPSL, UVSQ Université Paris-Saclay, Sorbonne Université, CNRS, Guyancourt, France.

${ }^{3}$ Space Science Exploration Division (Code 690), NASA Goddard Space Flight Center, Greenbelt, Maryland, USA.

${ }_{5}^{4}$ Department of Geological Sciences, University of Florida, Gainesville, Florida, USA.

${ }^{5}$ Georgetown University, Washington, District of Columbia, USA.

${ }^{6}$ Telespazio France, Toulouse, France.

${ }^{7}$ Laboratoire Interuniversitaire des Systèmes Atmosphériques (LISA), UMR CNRS 7583, Université Paris Est Créteil et Université de Paris, Institut Pierre Simon Laplace, Créteil, France.

${ }^{8}$ LGPM, CentraleSupélec, SFR Condorcet FR CNRS 3417, Centre Européen de Biotechnologie et de Bioéconomie (CEBB), Université Paris-Saclay, Pomacle, France.

${ }^{9}$ Instituto de Ciencias Nucleares, Universidad Nacional Autónoma de México, Circuito Exterior, Ciudad Universitaria, Ciudad de México, Mexico.
} 
$\mathrm{Ca}\left(\mathrm{ClO}_{4}\right)_{2}$ to $\mathrm{Mg}\left(\mathrm{ClO}_{4}\right)_{2}$ phases. Later, chlorine-bearing compounds were detected by the Sample Analysis at Mars (SAM) instrument, 1 of 10 instruments on the Mars Science Laboratory Curiosity rover, such as hydrogen chloride $(\mathrm{HCl})$ gas, chloromethane, dichloromethane, chlorobenzene (Ming et al., 2014), and isomers of dichlorobenzene (Millan et al., 2019). These chlorine-bearing hydrocarbons have been attributed to the reaction of oxychlorine-related species with organic compounds during the pyrolysis of the samples analyzed with SAM (Freissinet et al., 2015; Millan et al., 2019). From these results, a reinterpretation of the data obtained with the gas chromatography-mass spectrometry (GC-MS) experiment onboard the 1976 Viking landers suggests that perchlorates and/or chlorates were also present in the samples analyzed by these experiments (Sutter et al., 2017a; Guzman et al., 2018). Furthermore, analysis of the Rocknest wind ripple with the SAM instrument and a comparison with results obtained from laboratory measurements indicate that calcium perchlorate is a better candidate for the perchlorate species than $\mathrm{Fe}, \mathrm{Mg}, \mathrm{Na}$ and $\mathrm{K}$ perchlorates (Leshin et al., 2013). More recently, chloride-bearing hydrocarbons have been produced by the reaction of oxychlorine-related species with organics in SAMs pyrolysis oven. This lead to the conclusion that in modern sand deposits and some much older rocks, $\mathrm{Ca}$ and $\mathrm{Mg}$ perchlorates are the most likely sources of chlorine-related products (Freissinet et al., 2015; Millan et al., 2019).

The detection of widespread perchlorates and likely chlorates on Mars led to several studies related to the potential effect of perchlorates on the detection of organic compounds with various instruments. Perchlorate is a strong oxidizing agent because oxygen can be released from the decomposition of perchlorates and could be the main cause of the degradation of organic compounds. The thermal decomposition of perchlorates, including lithium, sodium, potassium, magnesium, iron, aluminum, and calcium perchlorates, has been analyzed by using a thermobalance from previous experiments (Marvin and Woolaver, 1945). Two possible mechanisms for the thermal decomposition of a perchlorate were proposed (Marvin and Woolaver, 1945): (1) by gradual hydrolysis of hydrated compounds to yield perchloric acid and an oxide, such as magnesium, iron, and aluminum perchlorates, and (2) by dehydration followed by decomposition to yield oxygen and chloride, as in the case of lithium $\left(\sim 440^{\circ} \mathrm{C}\right)$, sodium $\left(\sim 480^{\circ} \mathrm{C}\right)$, potassium $\left(\sim 540^{\circ} \mathrm{C}\right)$, and calcium $\left(\sim 405^{\circ} \mathrm{C}\right)$ perchlorates. The salts may be dehydrated first and then decomposed when the temperature is high enough to force their release.

The temperature of oxygen release from perchlorate can be affected by other minerals present in a solid sample. For example, the decomposition temperature of calcium perchlorate or another oxychlorine species can decrease due to the presence of iron phases (Bruck et al., 2014; Hogancamp et al., 2018). Regardless of the perchlorate phase, oxygen will be released from any perchlorate in solid samples on Mars when the SAM instrument ovens are heated, leading to the oxidation of organic compounds into carbon dioxide. The main consequence of this is that organic matter is degraded and would not be detected (Ming et al., 2014). Furthermore, the abundance of oxychlorides varies by one order of magnitude (Farley et al., 2016). Some experiments have shown that there should be a minimum ratio of $4.7: 1$ between organic matter and perchlorate to ensure the detection of organic molecules with pyrolysis-gas chromatography coupled to mass spectrometry (Pyr-GC-MS) (Kounaves et al., 2014a) without major impact from the perchlorate. In addition, $\mathrm{HCl}$ produced during the thermal decomposition of martian perchlorate can react with soil carbonates leading to low temperature inorganic $\mathrm{CO}_{2}$ release, and the presence of calcium chloride $\left(\mathrm{CaCl}_{2}\right)$, which is formed from the reaction between calcite and $\mathrm{HCl}$, has been confirmed by X-ray diffraction experiments (Cannon et al., 2012). Therefore, the detection of organic fragments, not $\mathrm{CO}_{2}$ alone, should be used as definitive evidence for organics in martian soils (Cannon et al., 2012).

Perchlorate not only affects the type and the number of organic compounds detected (Steininger et al., 2012), it can also react with organic compounds to form chlorine-related compounds. For example, Guzman et al. (2018) observed the presence of chlorobenzene at a concentration of 0.08-1.0 ppb (relative to sample mass) in Viking Lander 2 (VL-2) data at a pyrolysis temperature between $350^{\circ} \mathrm{C}$ and $500^{\circ} \mathrm{C}$. They concluded that the reaction of indigenous organic carbon and instrument contamination with martian perchlorate during the pyrolysis process is the likely source of the chlorobenzene. Laboratory experiments confirm that perchlorates mixed with organic molecules with different molecular weights (low, medium, or high) will form chloride-related gases such as $\mathrm{HCl}$, carbonyl dichloride $\left(\mathrm{CCl}_{2} \mathrm{O}\right)$, and carbon tetrachloride $\left(\mathrm{CCl}_{4}\right)$ (Sephton et al., 2014). However, Montgomery et al. (2019) reported that the presence of perchlorate and other oxyanion salts inhibited the detection of organic compounds when analyzed by PyrGC-MS; removing perchlorates and sulfates of Atacama Desert showed identifiable biomarkers associated with cyanobacteria.

Both the Mars Organic Molecule Analyzer (MOMA) instrument onboard the ESA/Roscosmos ExoMars rover and the SAM instrument on the NASA Curiosity rover can detect organic molecules. MOMA and SAM are analytical suites that utilize Pyr-GC-MS. MOMA carries three derivatization/thermochemolysis agents (Goesmann et al., 2017), that is, N-tert-butyldimethylsilyl-N-methyltrifluoroacetamide/ $\mathrm{N}, \mathrm{N}$-dimethylformamide (MTBSTFA/DMF, for carboxylic and amino acids, nucleobases, amines, and alcohols), DMF dimethyl acetal (for amino acids, fatty acids, and primary amines with chiral centers), and tetramethylammonium hydroxide (TMAH) in methanol (for lipids and fatty acids, when driven to higher temperatures). SAM carries only MTBSTFA/DMF and TMAH in methanol (Mahaffy et al., 2012). These derivatization/thermochemolysis agents increase the volatility of organic molecules with labile groups, such as amino acids, carboxylic acids, and nucleobases (He et al., 2019a, 2020). TMAH is very useful for the liberation of polar molecules from macromolecules and the volatilization of fatty acids, but the decomposition of TMAH at elevated temperatures above $500^{\circ} \mathrm{C}$ (Morisson et al., 2017) can cause additional issues that complicate organics detection. The degradation of TMAH at relatively low temperatures (lower than $200^{\circ} \mathrm{C}$ ) has been studied, and different TMAH degradation mechanisms have been reported (Musker, 1967; Chempath et al., 2008, 2010; Long and Pivovar, 2012), but no study has reported on the by-products of TMAH pyrolysis at elevated temperatures. 
The thermal degradation of TMAH can proceed via two different pathways. The first pathway is a nucleophilic substitution reaction mechanism (the bimolecular or $\mathrm{S}_{\mathrm{N}} 2$ pathway) defined by the synchronous formation of one bond as another bond is broken. In this case, it is the nucleophilic attack by $\mathrm{OH}^{-}$on the $\mathrm{CH}_{3}$ group that produces trimethylamine (TMA) and dimethyl ether (Musker, 1967). The second pathway is the ylide one wherein the decomposition of TMAH to give TMA and dimethyl ether results from the initial removal of a proton from the quaternary ammonium salt, followed by the decomposition of the resulting ylide (Musker, 1964). For example, Macomber et al. (2008) did experiments with D-labeled TMAH to work out the mechanism of TMAH decomposition, using differential scanning calorimetry (DSC), thermal gravimetry (TG), and evolved gas analysis (EGA). They concluded that TMA, methanol, and dimethyl ether were the main resulting products. The extraction of the $\alpha$-proton to generate a nitrogen ylide is an important degradation mechanism for methyl ammonium species. Deprotonation of the tetramethyl ammonium ion by hydroxide establishes a rapid equilibrium between the tetramethylammonium ion and the nitrogen ylide species and water that combines the deuterium with the proton in the methyl groups. Then, the methoxide formed in this way reacts with $\left[\mathrm{Me}_{4} \mathrm{~N}\right]^{+}$via an $\mathrm{S}_{\mathrm{N}} 2$ process to generate dimethyl ester.

However, Chempath et al. (2008) proposed that the ylide pathway is more reasonable than the $S_{N} 2$ pathway. These researchers performed Thermogravimetry and mass spectrometry (TG-MS) experiments to evaluate the stability of tetramethylammonium $\left(\left[\mathrm{N}\left(\mathrm{CH}_{3}\right)_{4}{ }^{+}\right]\right)$under aqueous conditions in the presence of $\mathrm{OH}^{-}$ions. They verified the $\mathrm{H}-\mathrm{D}$ exchange, and their results demonstrated that the ylide mechanism plays a crucial role on the decomposition of TMAH. Moreover, they confirmed this pathway by calculation of the energy of the activation barrier, and they proved that it is lower than for the $S_{N} 2$ pathway. Finally, the ylide pathway can give rise to unstable intermediates with side reaction, including the Stevens rearrangement reactions (Surpateanu et al., 1976), Sommelet-Hauser rearrangement, and Hofmann elimination (Chempath et al., 2010).

The Hofmann elimination is a vulnerable pathway for degradation of n-alkyl-tetramethylammonium $\left(\mathrm{TMA}^{+}\right)$cations (Long and Pivovar, 2012). However, this barrier is also found to depend on the carbon chain length because of steric interference and number of hydrogens susceptible to the Hofmann elimination (Long and Pivovar, 2012). $\mathrm{OH}^{-}$can attack the $\alpha$-carbon atom and the cation degrades by the $\mathrm{S}_{\mathrm{N}} 2$ pathways. Edson et al. (2012) studied the effect of the number of $\beta$-hydrogen atoms susceptible to the Hofmann elimination and the mechanism of different alkyltrimethylammonium cations in deuteroxide form using EGA (Fig. 1). The Hofmann elimination is the preferred decomposition pathway for ammonium cations bearing $\beta$ hydrogens, and ylide formation reorganizes protons from water into TMA that is formed with a low activation barrier. The stability of cations increased with the blocking of $\beta$-hydrogens, and without $\beta$-hydrogen, $S_{\mathrm{N}} 2$ reactions occurred, as shown in Fig. 1. However, no studies report the degradation mechanism of TMAH at high temperature.

To distinguish the source of chlorinated organic compounds detected by the SAM instrument (Eigenbrode et al., 2018), Miller et al. (2015) evaluated possible carbon sources with and without the Tenax ${ }^{\circledR}$ trap, which is used to con- centrate the evolved species from the martian samples. They found that perchlorates have nearly no effect on the Tenax trap onboard SAM when the trap is not heated above $300^{\circ} \mathrm{C}$. In laboratory experiments, there is rare degradation of the trap after hundreds of pyrolysis experiments of Mars analog soils doped with perchlorates (calcium perchlorate, magnesium perchlorate, or iron chloride). Moreover, the effect of calcium perchlorate on the degradation of Tenax and the subsequent by-products have been studied (Buch et al., 2019). The by-products of perchlorates have an impact on the degradation products of Tenax, such as chlorinated phenyl molecules, chlorobenzaldehyde, chlorophthalic acid, and chlorobiphenyl. To date, few studies have reported on the effect of perchlorate on the function of derivatization agents, especially TMAH, at high temperature $\left(600^{\circ} \mathrm{C}\right)$. Thus, the influence of perchlorate on the function of TMAH thermochemolysis must be studied to best understand the potential influence of perchlorates on the TMAH experiment on the SAM and MOMA instruments.

This study explores the degradation of TMAH and the effect of calcium perchlorate on TMAH pyrolysis at $600^{\circ} \mathrm{C}$ (with different heating ramps, including flash pyrolysis and SAM-like ramp pyrolysis at $35^{\circ} \mathrm{C} \cdot \mathrm{min}^{-1}$ ) using Pyr-GC-MS with a hydrocarbon trap. From these results, we propose a mechanism for TMAH degradation at a high pyrolysis temperature $\left(600^{\circ} \mathrm{C}\right)$ in the presence of calcium perchlorate. These results provide important foundational data for the interpretation of the origin of organic molecules detected by SAM and MOMA.

\section{Experimental Design}

\subsection{Samples and chemical products}

A TMAH solution (25\% by weight in methanol; SigmaAldrich) was used in this study, and calcium perchlorate tetrahydrate (99\%; Sigma-Aldrich) was used to make the calcium perchlorate solution. Naphthalene-d8 (isotopic purity, 99 atom \% D; Sigma-Aldrich) was used as an internal standard (IS). The concentration of calcium perchlorate solution $\left(0.85 \mathrm{~mol} \cdot \mathrm{L}^{-1}\right)$ was measured by atomic absorption spectrometry (Varian Australia Pty Ltd) (Zagatto et al., 1979; Milačič et al., 1992; Fayiga and Ma, 2006; Špirić et al., 2013), using air-acetylene flame test, with a calcium cathode lamp set at the $422.7 \mathrm{~nm}$ resonance wavelength.

The abundance of $\mathrm{ClO}_{4}{ }^{-}$in TMAH solution (wt \%) is given by the following equation:

$$
A=\frac{2 C_{\mathrm{Ca}\left(\mathrm{ClO}_{4}\right)_{2}} \cdot V_{\mathrm{Ca}\left(\mathrm{ClO}_{4}\right)_{2}} \cdot M_{\mathrm{ClO}_{4}^{-}}}{V_{T M A H} \cdot \rho_{T M A H}} \times 100 \%,
$$

where $\mathrm{A}$ is the abundance of $\mathrm{ClO}_{4}^{-}$in wt \%; $\mathrm{C}_{\mathrm{Ca}\left(\mathrm{ClO}_{4}\right)_{2}}$ is the concentration of $\mathrm{Ca}\left(\mathrm{ClO}_{4}\right)_{2}$ solution, $0.85 \mathrm{~mol} \cdot \mathrm{L}^{-1} ; \mathrm{M}_{\mathrm{ClO}_{4}^{-}}$ is the molar mass of $\mathrm{ClO}_{4}{ }^{-}, 99.45 \mathrm{~g} \cdot \mathrm{mol}^{-1} ; \mathrm{V}_{\mathrm{Ca}\left(\mathrm{ClO}_{4}\right)_{2}}$ is the volume of $\mathrm{Ca}\left(\mathrm{ClO}_{4}\right)_{2}$ solution; $V_{T M A H}$ is the volume of TMAH solution, $3 \mu \mathrm{L}$; and $\rho_{T M A H}$ is the density of TMAH solution, $0.866 \mathrm{~g} \cdot \mathrm{mL}^{-1}$.

The effect of different wt \% of $\mathrm{ClO}_{4}^{-}(0.1,0.5,1.0,2.0$, $3.0,4.0,5.0,10.0,15.0,20.0,30.0,40.0 \mathrm{wt} \%)$ on TMAH pyrolysis at $600^{\circ} \mathrm{C}$ was studied. The calcium perchlorate was dried at room temperature under a dinitrogen flow for $3 \mathrm{~h}$, and the water abundance in the sample was measured by the Karl Fischer method with an Aqua processeur 


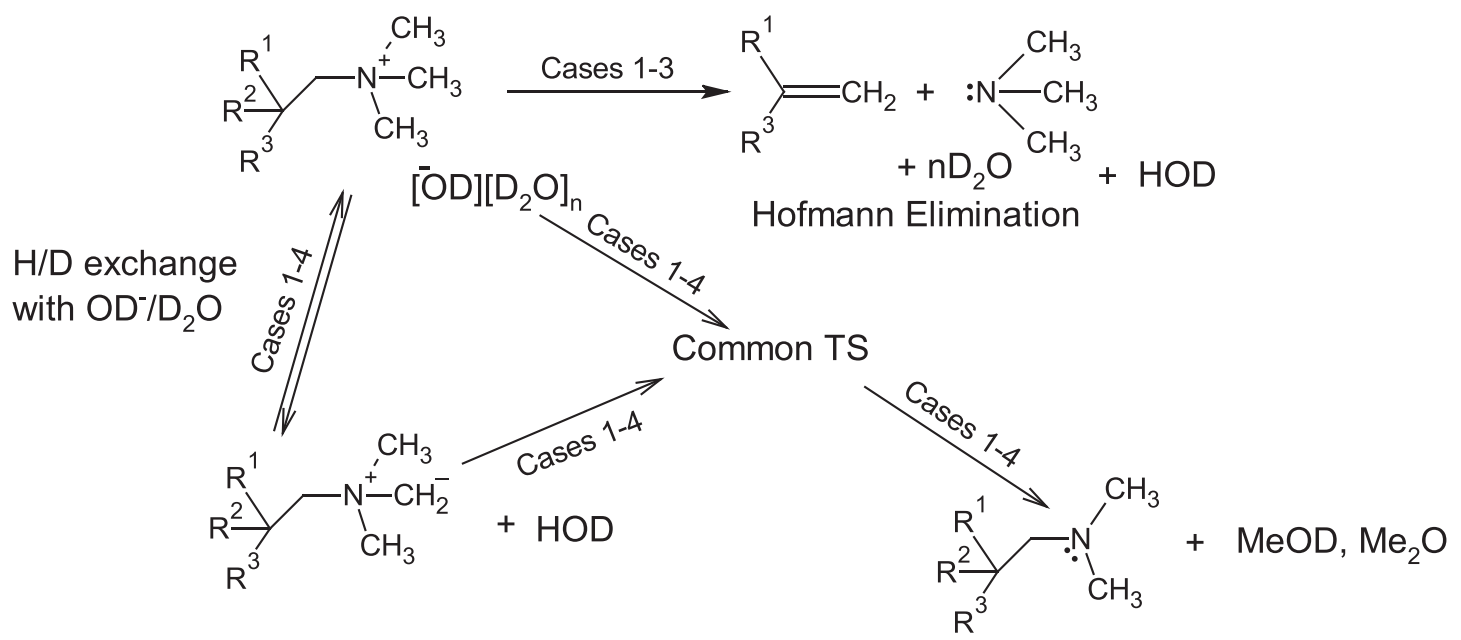

FIG. 1. Thermal decomposition of alkyltrimethylammonium deuteroxide, adapted from Edson et al. (2012). Case 1: $\mathrm{R}^{1}$, $\mathrm{R}^{2}$, and $\mathrm{R}^{3}=\mathrm{H}$; Case 2: $\mathrm{R}^{1}=\mathrm{CH}_{3}, \mathrm{R}^{2}$, and $\mathrm{R}^{3}=\mathrm{H}$; Case $3: \mathrm{R}^{2}=\mathrm{H}, \mathrm{R}^{1}$, and $\mathrm{R}^{3}=\mathrm{CH}_{3} ;$ Case $4: \mathrm{R}^{1}, \mathrm{R}^{2}$, and $\mathrm{R}^{3}=\mathrm{CH}_{3}$. TS, transition state.

radiometer (Seaman et al., 1949; Burns and Muraca, 1962; Bryan and Bhaskara, 1976; Galletti and Piccaglia, 1988; Ewa and Piotr, 2009). The calibration curve of the moisture detection is shown in Fig. 2. Results show that the content of moisture within the capsule is less than $1.6 \%$ and $0.7 \%$ when the calcium perchlorate abundance is 40 and $15 \mathrm{wt} \%$, respectively, which ensured that the experimental conditions are more Mars like.

Individual solutions of octanoic acid (C8, $\geq 98 \%$; SigmaAldrich), nonanoic acid, Kosher (C9, $\geq 96 \%$; SAFC), decanoic acid (C10, $\geq 98.0 \%$; Sigma Grade), undecanoic acid (C11, $\geq 97.0 \%$; Fluka), lauric acid (C12, $\geq 98.0 \%$; SigmaAldrich), tridecanoic acid (C13, $\geq 98.0 \%$; Sigma Grade), myristic acid (C14, 99-100\%; Sigma Grade), pentadecanoic acid (C15, 99\%; Sigma Grade), palmitic acid (C16, $\geq 99.0 \%$; Sigma Grade), heptadecanoic acid (C17, $\geq 98.0 \%$; Sigma Grade), stearic acid (C18, $\geq 98.5 \%$; Sigma Grade), and arachidic acid (C20, $\geq 99.0 \%$; Sigma-Aldrich) were prepared by diluting the pure fatty acids into pyridine ( $\geq 99.9 \%$; Sigma-Aldrich) solvent. The concentration of each fatty acid is $0.67 \mathrm{mmol} \cdot \mathrm{L}^{-1}$. For the recovery of fatty

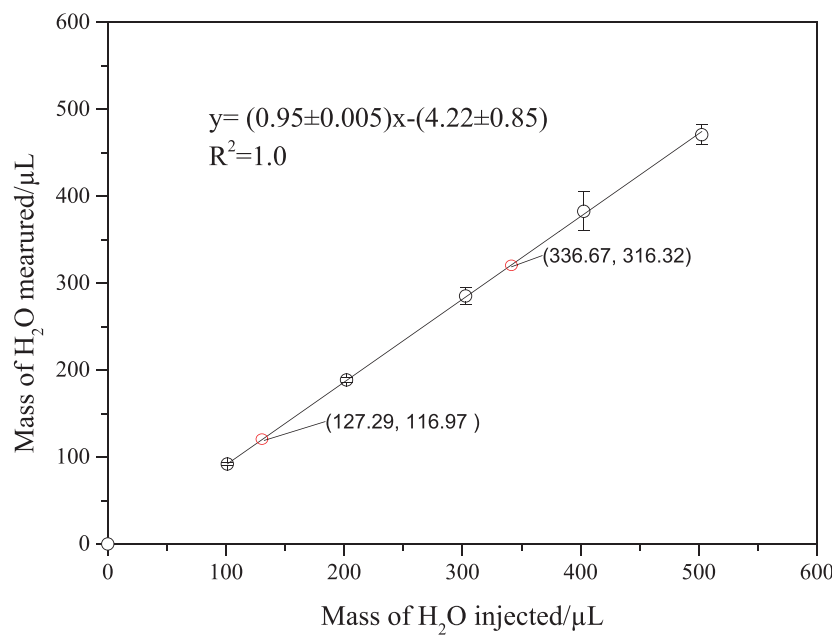

FIG. 2. The calibration curve of $\mathrm{H}_{2} \mathrm{O}$ detection. acids with $3 \mu \mathrm{L}$ TMAH, $2 \mu \mathrm{L}$ of the fatty acid solution was used. For the recovery of fatty acids under similar conditions used on Mars by the SAM and MOMA instruments, the original fatty acids solution was diluted to 1000 times, about $2.2 \mu \mathrm{L}$ of diluted fatty acid solution and $0.2 \mathrm{mg}$ of $\mathrm{ClO}_{4}{ }^{-}$were used, respectively.

\subsection{Pyrolysis experiments}

The pyrolysis experiments were performed with an EGA/ PY-3030 D micro-oven pyrolyzer (Frontier Lab), installed on the split/splitless (SSL) injector of a Trace GC Ultra gas chromatograph (Thermo Scientific) coupled to a quadrupole mass spectrometer (ISQ LT; Thermo Scientific). Varying volumes of $\mathrm{Ca}\left(\mathrm{ClO}_{4}\right)_{2}$ solution were injected in a capsule (Eco-Cup; Frontier Lab) under a stream of nitrogen to dry the $\mathrm{Ca}\left(\mathrm{ClO}_{4}\right)_{2}$ solution, and then, $3 \mu \mathrm{L}$ of TMAH was injected into the capsule. That capsule carried by an eco-stick (Frontier Lab) was attached to the top of the pyrolyzer.

Two kinds of pyrolysis ramps were used in this study. The first one is flash pyrolysis wherein the sample is pushed into a heated and stabilized oven at $600^{\circ} \mathrm{C}$ for $30 \mathrm{~s}$, after which the sample is removed from the oven. Helium is used as the carrier gas to carry the pyrolysis volatile products into the GC-MS. The second ramp is the SAM-like ramp pyrolysis. During this process, the heart-cut EGA analysis method was used. For that, the sample cup was attached to the pyrolyzer and the pyrolyzer head space was purged for 2 min before proceeding. Then, the sample cup was pushed inside the oven (initial temperature was $50^{\circ} \mathrm{C}$ ), and the oven was heated to the final temperature of $600^{\circ} \mathrm{C}$ (with a 1 min hold) at the SAM heating rate of $35^{\circ} \mathrm{C} \cdot \mathrm{min}^{-1}$. The MicroJet CryoTrap (Frontier Lab) was used to trap and preconcentrate at $-180^{\circ} \mathrm{C}$ all the released products. When the pyrolysis process was finished, the temperature of the trap was quickly increased to $40^{\circ} \mathrm{C}$. Then, all the products were released and sent to the GC-MS through the helium flow.

Finally, to explore the products of TMAH pyrolysis with calcium perchlorate, a stepped pyrolysis of TMAH with and without calcium perchlorate was performed. For this study, the sample was injected into the pyrolyzer and was heated at 
a SAM-like heating rate of $35^{\circ} \mathrm{C} \cdot \mathrm{min}^{-1}$ from $50^{\circ} \mathrm{C}$ to $100^{\circ} \mathrm{C}$, every increase in $100^{\circ} \mathrm{C}$ up to $1000^{\circ} \mathrm{C}$, as 100 $200^{\circ} \mathrm{C}, 200-300^{\circ} \mathrm{C}, 300-400^{\circ} \mathrm{C}, 400-500^{\circ} \mathrm{C}, 500-600^{\circ} \mathrm{C}$, $600-700^{\circ} \mathrm{C}, 700-800^{\circ} \mathrm{C}, 800-900^{\circ} \mathrm{C}$, and $900-1000^{\circ} \mathrm{C}$. All experiments were repeated more than three times.

\subsection{GC-MS analysis}

Analyses were conducted with a Trace GC Ultra gas chromatograph (Thermo Scientific) coupled to a quadrupole mass spectrometer (ISQ LT; Thermo Scientific). The GC is equipped with a Supelco SLB-5MS Inferno column ( $30 \mathrm{~m} \times 0.25 \mathrm{~mm}$ i.d. $\times 0.25 \mu \mathrm{m}$ film thickness) with $5 \mathrm{~m}$ integrated guard column. For the flash pyrolysis, the temperature programming of the column starts at $40^{\circ} \mathrm{C}$ held for $2 \mathrm{~min}$, then at a heat rate of $3^{\circ} \mathrm{C} \mathrm{min}^{-1}$ up to $200^{\circ} \mathrm{C}$ and then raised to $300^{\circ} \mathrm{C}$ at a rate of $6^{\circ} \mathrm{C} \mathrm{min}$ min $^{-1}$ and maintained for $1 \mathrm{~min}$. To mimic the SAM ramp, the temperature programming of the column starts at $40^{\circ} \mathrm{C}$ hold for $2 \mathrm{~min}$, then at a heat rate of $6^{\circ} \mathrm{C} \mathrm{min}-1$ up to $300^{\circ} \mathrm{C}$ and maintained $1 \mathrm{~min}$. In both ramps, helium was used as the carrier gas and the helium flow rate in the column was $1.2 \mathrm{~mL} \cdot \mathrm{min}^{-1}$. The split flow was $24 \mathrm{~mL} \cdot \mathrm{min}^{-1}$. The temperature of the SSL injector was set at $280^{\circ} \mathrm{C}$. The masses were scanned between $\mathrm{m} / \mathrm{z} 40$ and $\mathrm{m} / \mathrm{z}$ 500. The ionization energy was $70 \mathrm{eV}$.

The relative abundance of the compounds was obtained through the following equation:

$$
C_{i}=\frac{\frac{A_{i}}{A_{i s}}}{\sum \frac{A_{i}}{A_{i s}}} \times 100 \%,
$$

where $A_{i}$ and $A_{i s}$ refer to the peak areas of the products and the peak area of the internal standard, respectively.

\section{Results}

\subsection{Flash pyrolysis of $\mathrm{TMAH}$ at $600^{\circ} \mathrm{C}$}

3.1.1. Products of TMAH treated with flash pyrolysis at $600^{\circ} \mathrm{C}$. Flash pyrolysis is a high temperature process, in which the sample is rapidly heated at a very high heating and heat transfer rate in the absence of air (Bridgwater and Peacocke, 2000). Samples treated with the flash pyrolysis method almost always yield a greater number and diversity of fatty acid methyl esters than ramped pyrolysis, because the flash pyrolysis step of macromolecules with TMAH thermochemolysis is higher efficient (Williams et al., 2019). Therefore, the flash pyrolysis products of TMAH at $600^{\circ} \mathrm{C}$ were analyzed. Figure 3 shows the chromatogram of TMAH flash pyrolysis at $600^{\circ} \mathrm{C}$, and all products released from flash pyrolysis are listed in Supplementary Table S1. Most of the by-products of TMAH pyrolysis were detected from the retention time (RT) of $1.0-5.0 \mathrm{~min}$; the naphthalene-d8 (internal standard) was eluted at the retention time of $14.80 \mathrm{~min}$. TMA (eluted at 2.06-2.29 min) and dimethyl ether (eluted at $1.95 \mathrm{~min}$ ) are the main products of TMAH flash pyrolysis degradation at $600^{\circ} \mathrm{C}$. The production yield of TMA and dimethyl ether is ca. $48 \%$ and $25 \%$, respectively, and carbon dioxide formed during the TMAH pyrolysis process accounts for $15 \%$ of all pyrolysis products from TMAH pyrolysis. Other nitrogen-bearing compounds account for $12 \%$ of all pyrolysis products from TMAH flash pyrolysis, such as N-methyl-ethylamine, N,N-dimethyl- ethylamine, and the N-O containing compounds such as urea. Various siloxane compounds were detected at different retention times of $6.60,6.80,10.69,11.0$, and $13.79 \mathrm{~min}$, which were caused by the column bleeding, a loss of its stationary phase (5\% diphenyl/95\% dimethyl siloxane).

During the flash pyrolysis of TMAH at $600^{\circ} \mathrm{C}$, radicals such as $\cdot \mathrm{H}, \cdot \mathrm{CH}_{3},: \mathrm{CH}_{2}, \cdot \mathrm{CH}_{2}\left(\mathrm{CH}_{3}\right)_{3} \mathrm{~N}^{+}$, and $\cdot \mathrm{CH}_{2}\left(\mathrm{CH}_{3}\right)_{2} \mathrm{~N}^{+}$ were formed because of the cracking of the bond of nitrogen and a methyl group, the $\mathrm{C}-\mathrm{H}$ bond in the methyl functional group, and the recombination of these radicals. For example, the hydrogen radicals stabilize the structure of $\left(\mathrm{CH}_{3}\right)_{2} \mathrm{~N}^{+} \mathrm{CH}_{2}-$ and TMA was formed (Wang and Liang, 2014). The Hoffman elimination plays a key role in alkene formation, the aromatization of alkenes producing aromatics, such as benzene, and N,N-dimethyl-benzenemethanamine formation from the combination of benzene radicals and $\left(\mathrm{CH}_{3}\right)_{2} \mathrm{~N}^{+} \mathrm{CH}_{2}-$. Methanol could be formed through the demethylation of TMAH and the combination of methyl functional group with the $\mathrm{OH}$ radicals, and dimethyl ether was formed through the dehydration of methanol. The aldehyde product $\left(\mathrm{CH}_{3}\right)_{3} \mathrm{~N}^{+} \mathrm{CHO}$ could be generated by the hydrolysis reaction of carbon center radicals, and the aldehyde products could be oxidized by the oxygen radicals from the system and to form the carboxylic acids at high temperature. The possible route of TMAH degradation is shown in Fig. 4.

3.1.2. Effect of $\mathrm{Ca}\left(\mathrm{ClO}_{4}\right)_{2}$ on flash pyrolysis of TMAH. As described previously, perchlorates have been detected on Mars, with calcium perchlorate thought to be the main source of chlorine (Ming et al., 2014). Therefore, the influence of calcium perchlorate on the pyrolysis behavior of TMAH was investigated; in particular, the pyrolysis behavior of TMAH with calcium perchlorate in different concentrations $(0.1,0.5,1.0,2.0,3.0,4.0,5.0,10.0$, and $15.0 \mathrm{wt} \%$ ) was studied. The resulting chromatograms are shown in Fig. 5. When the perchlorate abundance is lower than $2 \mathrm{wt} \%$, few new products are formed during the flash pyrolysis of TMAH. When the abundance of perchlorate is higher than $2 \mathrm{wt} \%$, new products are detected such as (dimethylamino)acetonitrile (RT: $5.33 \mathrm{~min}$ ) and dimethyl cyanamide (RT: $5.80 \mathrm{~min}$ ) with the $\mathrm{C} \equiv \mathrm{N}$ bond, DMF with the aldehyde functional group eluted at $6.26 \mathrm{~min}$, and $1,3,5-$ trimethyl-1,3,5-triazacyclohexane (TMTAC) with a sixmembered heterocyclic aromatic ring eluted at $11.10 \mathrm{~min}$. Pyrrole was formed during the pyrolysis of TMAH, such as 2,5dimethyl-pyrrole at the retention time of $7.49 \mathrm{~min}$ and 4ethyl-2-methyl-pyrrole at the retention time of $9.83 \mathrm{~min}$. The products of TMAH pyrolysis with calcium perchlorate at a concentration higher than $10 \mathrm{wt} \%$ are listed in Supplementary Table S2. There are only three possible Cl-containing compounds at low abundance detected in this study, including 5-chloro-2-pyridinol $(\mathrm{RT}=10.12$, $12.57 \mathrm{~min}), 5$-chloro-1-methylimidazole ( $\mathrm{RT}=10.18,12.0$, and $12.69 \mathrm{~min}$ ), and 4,5-dichloro-1-methyl-imidazole (RT= $15.72 \mathrm{~min}$ ). The intensity of these peaks is at the detection limit of the instrument.

The distribution of the main products of TMAH flash pyrolysis with $10 \mathrm{wt} \%$ calcium perchlorate is shown in Table 1. Most of the products are N-containing compounds. These include TMA, N,N,N', $\mathrm{N}^{\prime}$-tetramethylmethanediamine, and TMTAC at $12.7 \%, 21.3 \%$, and $16.7 \%$, 


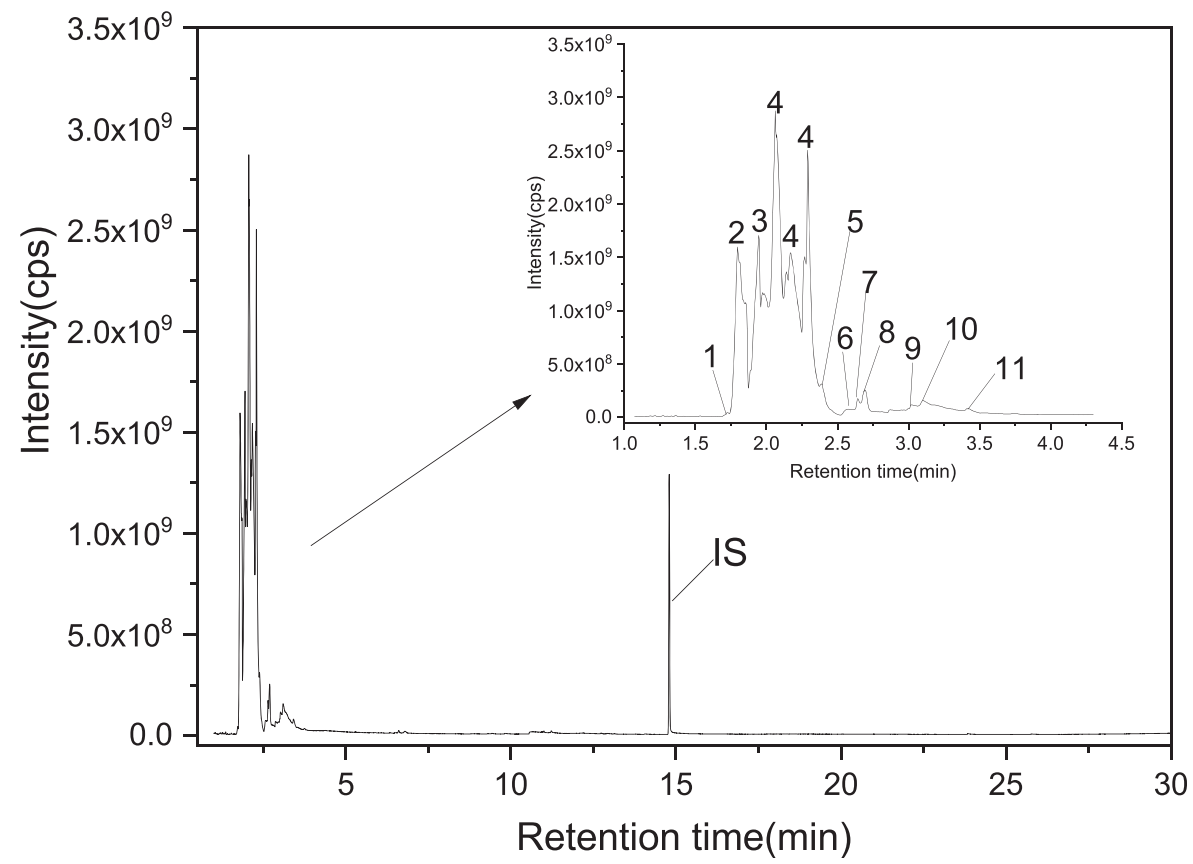

FIG. 3. The chromatogram of TMAH flash pyrolysis at $600^{\circ} \mathrm{C}$. Peak 1: $\mathrm{CO}_{2}$; peak 2: 3Aminobutanoic acid; peak 3: Dimethyl ether; peak 4: TMA (and isomers); peak 5: Dimethyoxymethane; peak 6: N-methylethylamine; peak 7: Urea; peaks 8 and 9: N,N-dimethyl-ethylamine; peak 10: Betaine; peak 11: 1,2Dimethoxy-ethane. IS, internal standard; TMA, trimethylamine; TMAH, tetramethylammonium hydroxide. respectively. Dimethyl ether and $\mathrm{CO}_{2}$ are also main products at $11.0 \%$ and $13.9 \%$, respectively. The newly formed products of dimethylamino acetonitrile and DMF, of $6.2 \%$ and $6.7 \%$, respectively, account for a relatively high proportion compared with other nitrogen-containing by-products.

Figure 6 shows the effects of calcium perchlorate on the main products produced during the flash pyrolysis of TMAH at $600^{\circ} \mathrm{C}$. TMA and dimethyl ether are the main compounds from the flash pyrolysis of TMAH with the presence of calcium perchlorate, as shown in Table 1, and their abundance did not show obvious changes with the increase of calcium perchlorate when its abundance is lower than $5 \mathrm{wt} \%$. TMA abundance increases as calcium perchlorate reaches $2 \mathrm{wt} \%$, and the TMA abundance remains stable as the calcium perchlorate concentration increases to $10 \mathrm{wt} \%$. However, TMA decreases with an increase of calcium

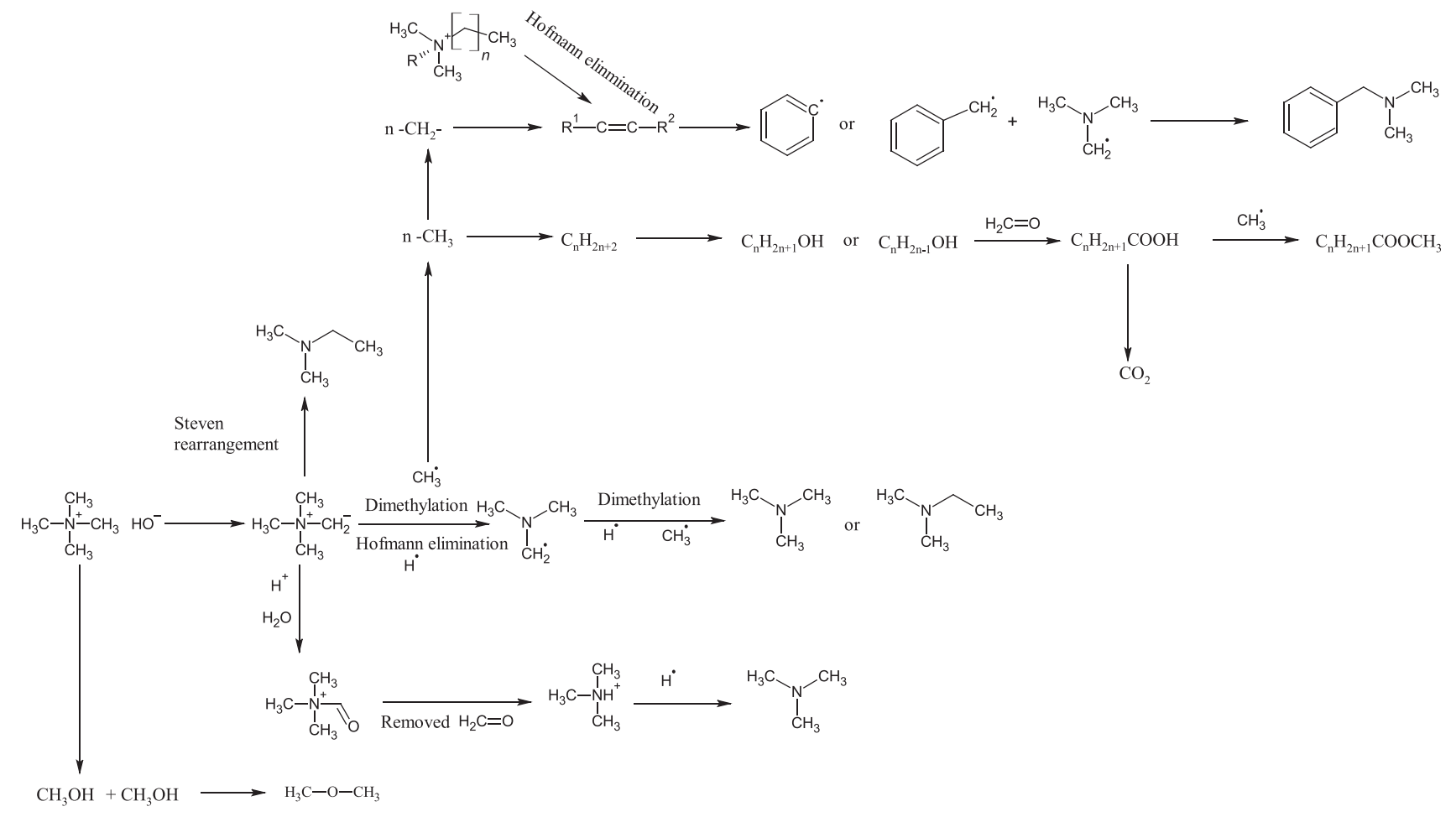

FIG. 4. The mechanism of TMAH degradation via flash pyrolysis. 
FIG. 5. Chromatograms of TMAH flash pyrolysis with $\mathrm{Ca}$ $\left(\mathrm{ClO}_{4}\right)_{2}$ in different abundances at $600^{\circ} \mathrm{C}$. Peak 1: Dimethyl ether; peak 2: 2-Methoxyethoxy-ethene; peak 3: $\mathrm{N}, \mathrm{N}$-dimethyl-methylamine and isomers; peak 4: Tetramethylammonium acetate; peak 5: 1-Methylaziridine; peak 6: N,N-dimethyl-ethylamine; peaks 7 and 8: $\mathrm{N}, \mathrm{N}, \mathrm{N}^{\prime}, \mathrm{N}^{\prime}-$ tetramethyl-methanediamine; peak 9: Dimethylamino-acetonitrile; peak 10: Dimethyl-cyanamide; peak 11: $\mathrm{N}$ methyl-N-(2-hydroxyethyl)carbamic acid, methyl ester; peak 12: N,Ndimethyl-formamide; peak 13: Propenal dimethylhydrazone; peak 14: 1-Methyl-3-piperidinol; peak 15: N,N-dimethylacetamide; peak 16: Hexahydro-1,3,5-trimethyl-1,3,5triazine (TMTAC); peak 17: Nmethyl-N-(2-hydroxyethyl)carbamic acid, methyl ether; peak 18: Benzoic acid, methyl ester; peak 19: N,N, 4-trimethyl-benzenemethanamine; peak 20: Hexadecanoic acid, methyl ester (palmitic acid, methyl ester); peak 21: Octadecanoic acid; methyl ester (stearic acid, methyl ester); peak 22: 2-Butenedioic $\operatorname{acid}(Z)$-diethyl ester (maleic acid diethyl ester).

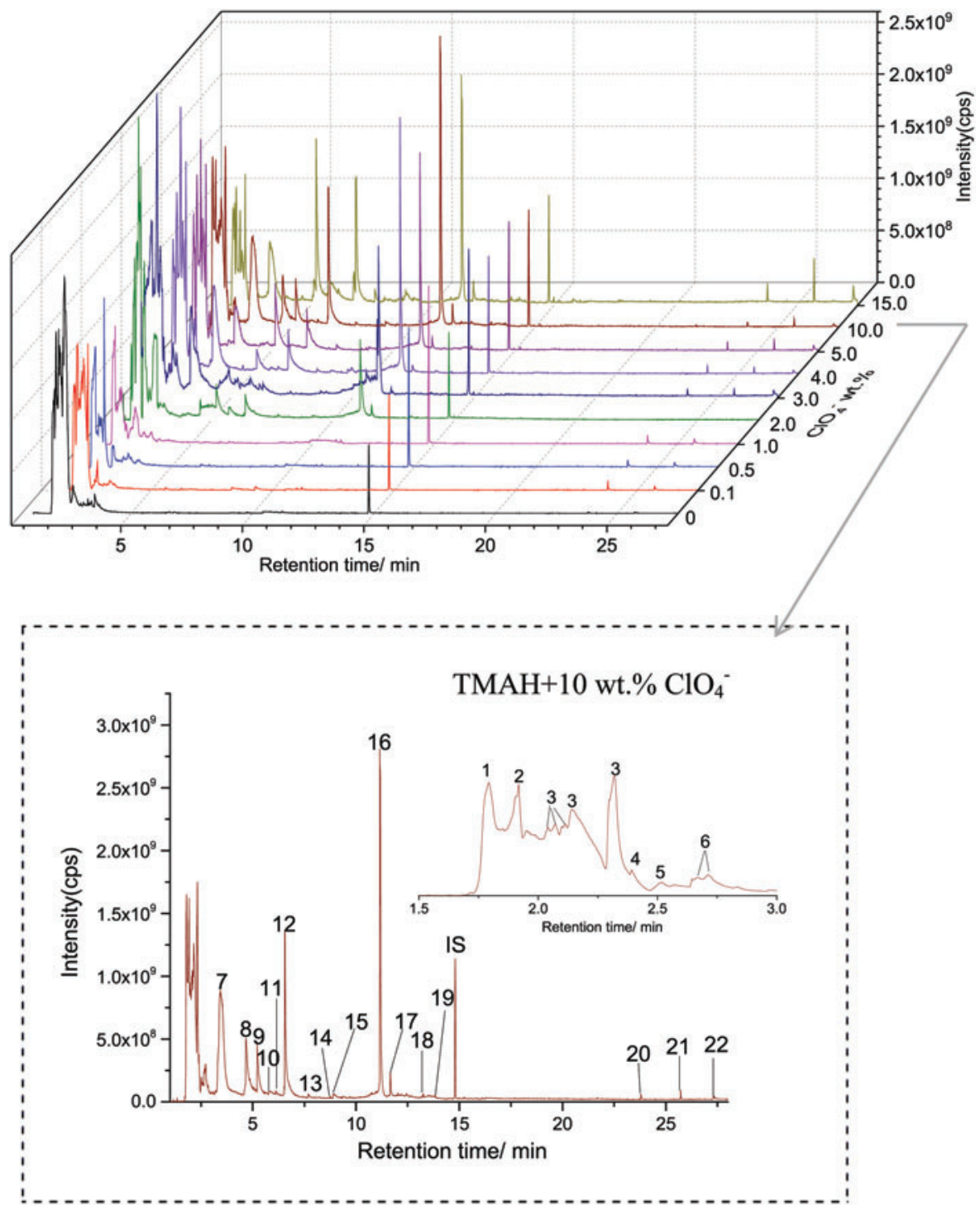

perchlorate up to $15 \mathrm{wt} \%$, which means that other $\mathrm{N}$-bearing compounds are formed. Dimethyl ether shows a similar trend as TMA.

Nitrogen-containing compounds such as DMF and dimethylamino acetonitrile, and TMTAC and dimethyl cyanamide are formed when calcium perchlorate is higher than $2 \mathrm{wt} \%$, and the yield of DMF and dimethylamino acetonitrile increases with an increase in calcium perchlorate when its abundance is higher than $5 \mathrm{wt} \%$. For example, the amount of DMF formed after the TMAH pyrolysis with the presence of $15 \mathrm{wt} \% \mathrm{ClO}_{4}^{-}$is $c a .2 .7$ times higher than that from TMAH pyrolysis with calcium perchlorate with the presence of $5 \mathrm{wt} \%$ $\mathrm{ClO}_{4}^{-}$; the TMTAC and dimethyl cyanamide show a slight increase with the increase of perchlorate higher than $5 \mathrm{wt} \%$. $\mathrm{N}, \mathrm{N}, \mathrm{N}^{\prime}, \mathrm{N}^{\prime}$-tetramethyl-methanediamine is one of the most important by-products from TMAH pyrolysis, and the abundance of $\mathrm{N}, \mathrm{N}, \mathrm{N}^{\prime}, \mathrm{N}^{\prime}$-tetramethyl-methanediamine increases with an increase in calcium perchlorate up to $10 \mathrm{wt} \%$. $\mathrm{N}, \mathrm{N}, \mathrm{N}^{\prime}, \mathrm{N}^{\prime}$-tetramethyl-methanediamine could possibly be decomposed or transferred to other nitrogen-containing compounds, such as cyanamide or triazine. 1-methoxy-3,3- diethyltriazene 2-oxide at the retention time of $11.66 \mathrm{~min}$ is an intermediate compound, and the abundance of N,N-dimethylethylamine increases slightly with increasing perchlorate concentration. And, N,N-dimethylbenzenamide was detected at a low concentration, indicating that additional perchlorate promotes the formation of these products.

\subsection{The pyrolysis of TMAH under SAM experimental conditions}

3.2.1. Products of TMAH pyrolysis under SAM experiment conditions. The chromatogram for TMAH pyrolysis using the SAM-like $\left(35^{\circ} \mathrm{C} \cdot \mathrm{min}^{-1}\right)$ heating ramp (Fig. 7) is similar to the results of TMAH flash pyrolysis from $50^{\circ} \mathrm{C}$ to $600^{\circ} \mathrm{C}$. Indeed, no compounds of interest were detected after $5 \mathrm{~min}$ retention time. TMA and dimethyl ether are the main products of TMAH pyrolysis. Other pyrolysis products of TMAH include nitrogen- and oxygen-containing compounds (Supplementary Table S3). Compared with TMAH flash pyrolysis, there are fewer by-products with TMAH pyrolysis at the SAM-like ramp. This is due to radical 
Table 1. The Distribution of the Pyrolysis Products of Tetramethylammonium Hydroxide with $10 \mathrm{wt} \%$ of Perchlorate During the Flash Pyrolysis at $600^{\circ} \mathrm{C}$

\begin{tabular}{lclc}
\hline Compounds & Yields $(\%)$ & \multicolumn{1}{c}{ Compounds } & Yields $(\%)$ \\
\hline Carbon dioxide & 13.9 & Dimethylamino-acetonitrile & 6.2 \\
Dimethyl ether & 11.0 & Dimethylformamide & 6.7 \\
Trimethylamine & 12.7 & Dimethyl-cyanamide & 1.0 \\
N,N-dimethyl-ethylamine & 1.3 & 1,3,5-Trimethyl-1,3,5-triazacyclohexane & 16.7 \\
N,N, $\mathrm{N}^{\prime}, \mathrm{N}^{\prime}$-tetramethylmethanediamine & 21.3 & 1-Methoxy-3,3-diethyltriazene-2-ox & 1.2 \\
Others & 8.0 & & \\
\hline
\end{tabular}

fragments being formed simultaneously and in a highly reactive state (Onay and Mete Kockar, 2003; He et al., 2014) during TMAH flash pyrolysis at $600^{\circ} \mathrm{C}$. Thus, the radicals interact with each other forming more by-products. The pyrolysis products of TMAH pyrolysis at $c a .135-140^{\circ} \mathrm{C}$ have been previously studied (Musker, 1964), with the main products of dimethyl ether and TMA being consistent with our study.

3.2.2. The effect of calcium perchlorate on TMAH under SAM-like pyrolysis experimental conditions. To study the effect of calcium perchlorate on TMAH pyrolysis under SAM-like ramp conditions $\left(35^{\circ} \mathrm{C} \cdot \mathrm{min}^{-1}\right.$ up to a final temperature of $600^{\circ} \mathrm{C}$ ), the pyrolysis products of TMAH with different calcium perchlorate concentrations were analyzed.
Figure 8 shows the chromatograms of TMAH pyrolysis with $\mathrm{Ca}\left(\mathrm{ClO}_{4}\right)_{2}$ at the SAM-like ramp from $50^{\circ} \mathrm{C}$ to $600^{\circ} \mathrm{C}$. Results show that chloromethane is formed during the pyrolysis of TMAH when calcium perchlorate concentrations are higher than $3 \mathrm{wt} \%$, and chloromethane abundance increases with an increase in calcium perchlorate percentage. This trend may be caused by the decomposition of tertramethylammonium chloride. This reaction (1) can be expressed by the following equation (Lawson and Collie, 1888):

$$
\left(\mathrm{CH}_{3}\right)_{4} \mathrm{NCl} \rightarrow\left(\mathrm{CH}_{3}\right)_{3} \mathrm{~N}+\mathrm{CH}_{3} \mathrm{Cl}
$$

Figure 9 shows the results of calcium perchlorate on TMAH pyrolysis at the SAM-like heating ramp. Dimethyl
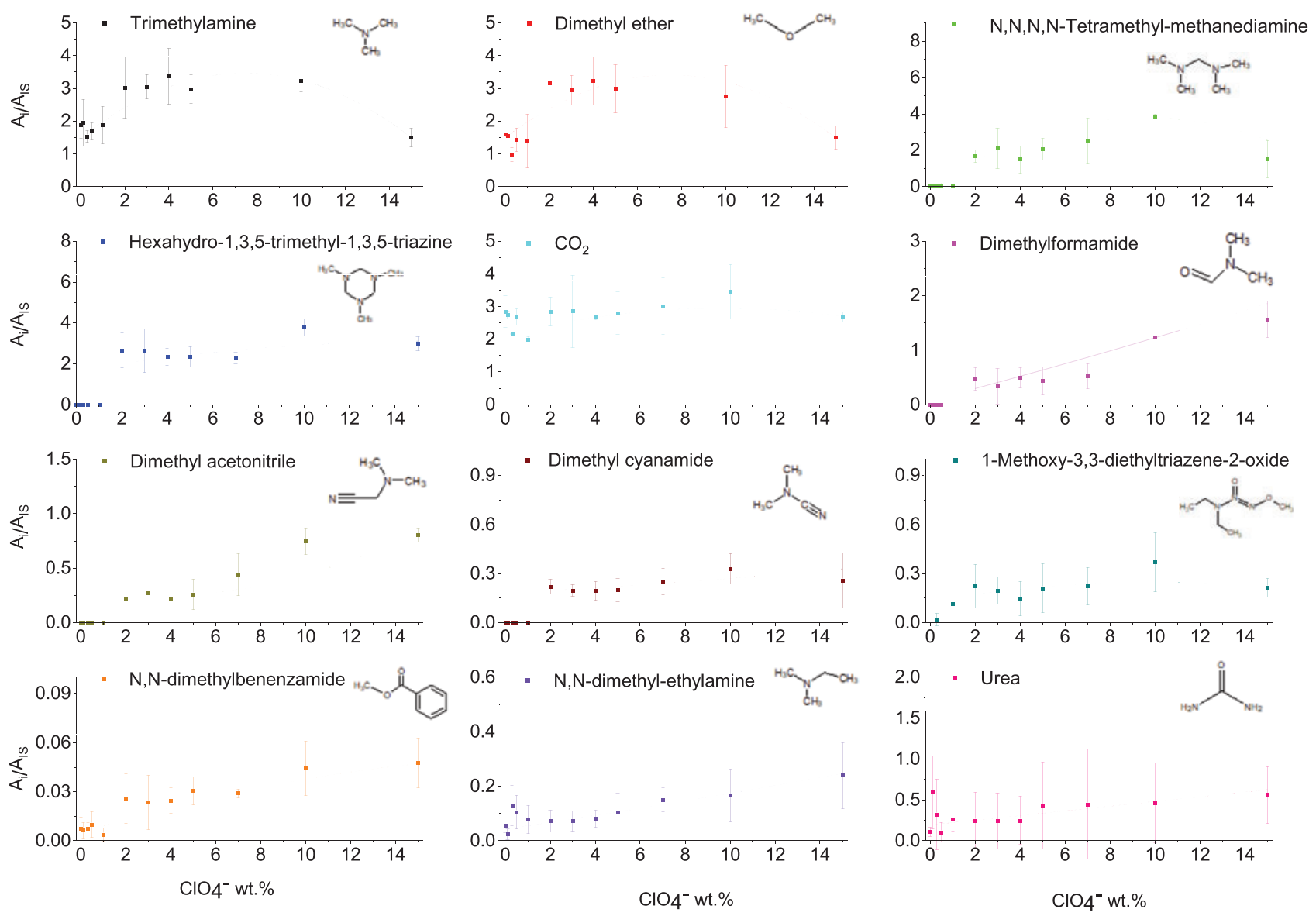

FIG. 6. Effect of perchlorate on the main products of TMAH flash pyrolysis at $600^{\circ} \mathrm{C}\left(\mathrm{A}_{\mathrm{i}} / \mathrm{A}_{\mathrm{IS}}\right.$ represents the peak area of the internal standard divided by the peak area of the target compounds). 
FIG. 7. Chromatography of TMAH pyrolysis at SAM-like ramp. Peak 1: $\mathrm{CO}_{2}$; peaks 2 and 4: Dimethyl ether; peak 3: Ethanedioic acid; peak 5: TMA (and isomers); peak 6: N,N-dimethyl-ethylamine; peak 7: $\mathrm{N}, \mathrm{N}^{\prime}$-dimethyl-ethylenediamine; peak 8: 2-Propanamine; peak 9: Diethylamine; peak 10: 2,2-Dimethoxy-ethanamine. SAM, Sample Analysis at Mars.

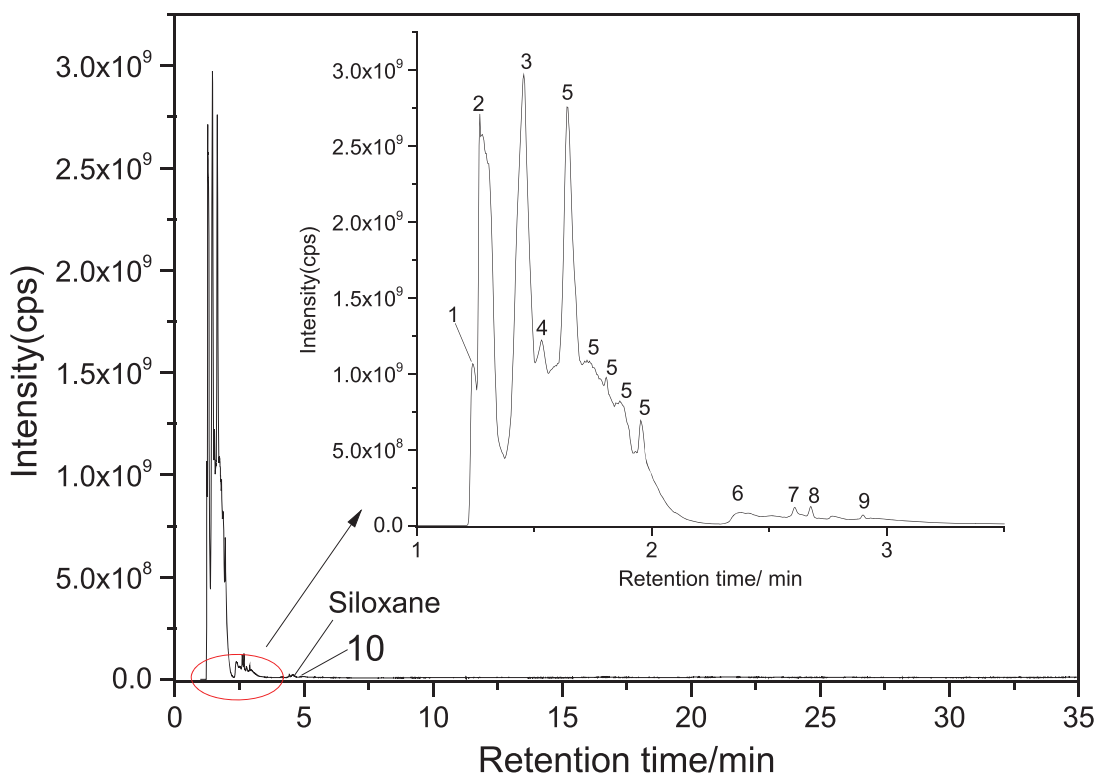

ether and TMA do not show obvious changes with the increase of calcium perchlorate until the perchlorate percentage is higher than $10 \mathrm{wt} \%$. After $10 \mathrm{wt} \%$ perchlorate, the abundance of dimethyl ether and TMA decreases slightly with the increase in perchlorates. At the same time, DMF and TMTAC are formed and become the main pyrolysis products, with a stable trend in their yield with the increase in calcium perchlorate. This demonstrates that the presence of calcium perchlorate can cause the formation of $\mathrm{N}$-containing compounds, and the transfer of $\mathrm{N}$ from TMA to other nitrogen-containing compounds was promoted. However, the reaction among these cracking fragments and how these by-products are formed during the TMAH flash pyrolysis and at SAM-like ramp pyrolysis need to be studied.

\section{Discussion}

\subsection{Mechanism of reaction of perchlorate with $T M A H$ during the pyrolysis}

To elucidate how calcium perchlorate influences the formation of by-products from TMAH pyrolysis at $600^{\circ} \mathrm{C}$, a step pyrolysis experiment was conducted to assess the products of TMAH with calcium perchlorate (at $20 \mathrm{wt} \%$ ) and without calcium perchlorate. Compared with the SAMlike pyrolysis products of TMAH, there was no obvious difference between the experiments except for the TMAH +20 wt $\% \mathrm{Ca}\left(\mathrm{ClO}_{4}\right)_{2}$ from the $400^{\circ} \mathrm{C}$ to $500^{\circ} \mathrm{C}$ temperature range (Fig. 10). Table 2 summarizes all products of TMAH with and without $20 \mathrm{wt} \%$ calcium perchlorate. TMA is the main pyrolysis product and was detected at temperature steps ranging from $100^{\circ} \mathrm{C}$ to $400^{\circ} \mathrm{C}$. This indicates that TMAH can be decomposed at temperatures as low as $c a$. $100^{\circ} \mathrm{C}$, and a variety of $\mathrm{N}$-bearing compounds was formed. In the $400-700^{\circ} \mathrm{C}$ range, lower abundances of TMA are detected. At temperatures higher than $800^{\circ} \mathrm{C}$, only $\mathrm{CO}_{2}$ was detected. In the $200-500^{\circ} \mathrm{C}$ range, chloromethane was detected at higher concentrations, indicating that methyl groups are formed during TMAH pyrolysis, as shown in Fig. 11.
Compared with TMAH-only experiment, the numbers of pyrolysis products were increased in TMAH SAM-like ramp pyrolysis in the presence of $20 \mathrm{wt} \% \mathrm{ClO}_{4}{ }^{-}$. Figure 11 shows the chromatograms of TMAH pyrolysis with the presence of 20 wt $\% \mathrm{ClO}_{4}^{-}$at different temperatures. Dimethyl ether and TMA are the main products of TMAH pyrolysis. There are also other $\mathrm{O}$ - and $\mathrm{N}$-containing compounds that were detected when the pyrolysis temperature was lower than $400^{\circ} \mathrm{C}$, such as 1-methoxy-2-(vinyloxy)-ethane and N,N-dimethylethylamine. There was no significant change in the number of by-products when the pyrolysis temperature was lower than $400^{\circ} \mathrm{C}$; however, more than 20 compounds were detected during the TMAH pyrolysis from the $400^{\circ} \mathrm{C}$ to $500^{\circ} \mathrm{C}$ temperature range. Approximately $50 \%$ of these compounds contain nitrogen. Among these compounds, a high concentration of TMTAC was detected. Other related nitrogencontaining and nitrogen-oxygen-containing compounds were identified, such as dimethyl-cyanamide, dimethylaminoacetonitrile, N-dimethyl-N-D-aspartic acid, pyrrole, and DMF. TMTAC, DMF, and TMA are the main products obtained from the pyrolysis of TMAH with $\mathrm{Ca}\left(\mathrm{ClO}_{4}\right)_{2}$, and the intensity of TMTAC is the highest, which means that the TMTAC is the most stable form of a nitrogen-containing compound in these experiments.

TMTAC, with a chair conformer with the axial orientation of one $\mathrm{CH}_{3}$ group based on electron diffraction data (Zverev et al., 2007), is a kind of nucleophilic acyl group transfer reagent and can provide a convenient alternative to the established dialkoxymethyllithium compounds and lithiodithianes commonly employed as one-carbon nucleophiles, a building block for imidazoles (Subramanian, 2001). It is well known that hexamethylenetetramine (HMT) or hexamine can be formed by the reaction of formaldehyde and ammonia, and they are stable intermediates during the reaction. Ogata and Kawasaki (1964) explained the mechanism and kinetics of the formaldehyde and ammonia reaction, wherein the formation of methylenediamine $\left(\mathrm{NH}_{2} \mathrm{CH}_{2} \mathrm{CH}_{2}\right)$ is faster than that of hexamine, and a higher ratio of $\mathrm{CH}_{2} \mathrm{O}$ versus $\mathrm{NH}_{3}$ is favorable for the formation of hexamine. They proposed the dimethylamine pathway for 


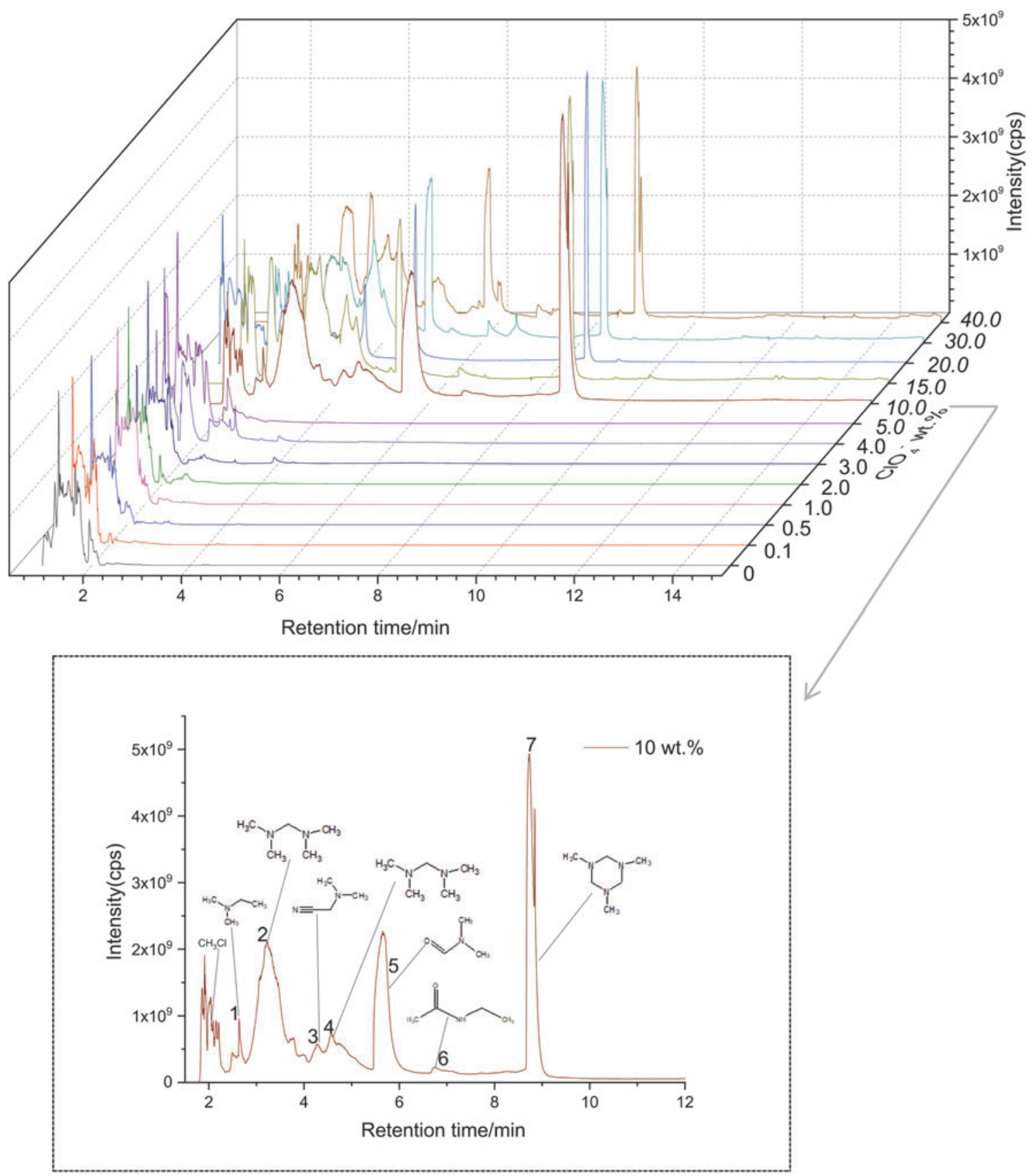

FIG. 8. Chromatograms of TMAH pyrolysis with $\mathrm{Ca}\left(\mathrm{ClO}_{4}\right)_{2}$ at SAM-like ramp. Peak 1: N,N-dimethyl-ethylamine; peaks 2 and 4: $\mathrm{N}, \mathrm{N}, \mathrm{N}^{\prime}, \mathrm{N}^{\prime}$-tetramethyl-methanediamine; peak 3: Dimethylamino-acetonitrile; peak 5: DMF; peak 6: N-ethylacetamide; peak 7: TMTAC.

the formation of HMT during the reaction of formaldehyde and ammonia, which has been confirmed by Zeffiro et al. (2016). Their results showed that dimethylamine plays a key role in the formation of HMT, which are stable intermediates. Through a dehydration process, methylenediamine reacts with dimethylamine and forms the cyclotrimethylenetriamine, which is the related heterocyclic compound of $\left(\mathrm{CH}_{2} \mathrm{NR}\right)_{3}$, where $\mathrm{R}$ is hydrogen; however, if $\mathrm{R}$ represents a methyl group, the product should be TMTAC.

This reaction led to the conclusion that the presence of aldehyde and amine functional group-containing compounds is key factor for the formation of TMTAC. Results from our study indicate that DMF, with both aldehyde and amine functional groups, could be the main compound formed simultaneously with the formation of TMTAC. Thus, we speculate that DMF is a vital intermediate and plays a key role in the formation of TMTAC. DMF is a polar solvent used widely in industrial processes that can dissolve a wide range of both organic and inorganic compounds because of its large dipole moment, a high dielectric constant, and its donor-acceptor properties (Attri et al., 2010). It can also be used as a dehydrating agent and catalyst in the dehydration of aldoximes to nitriles (Supsana et al., 2007). The oxygen atom in DMF is the negative pole and is an 


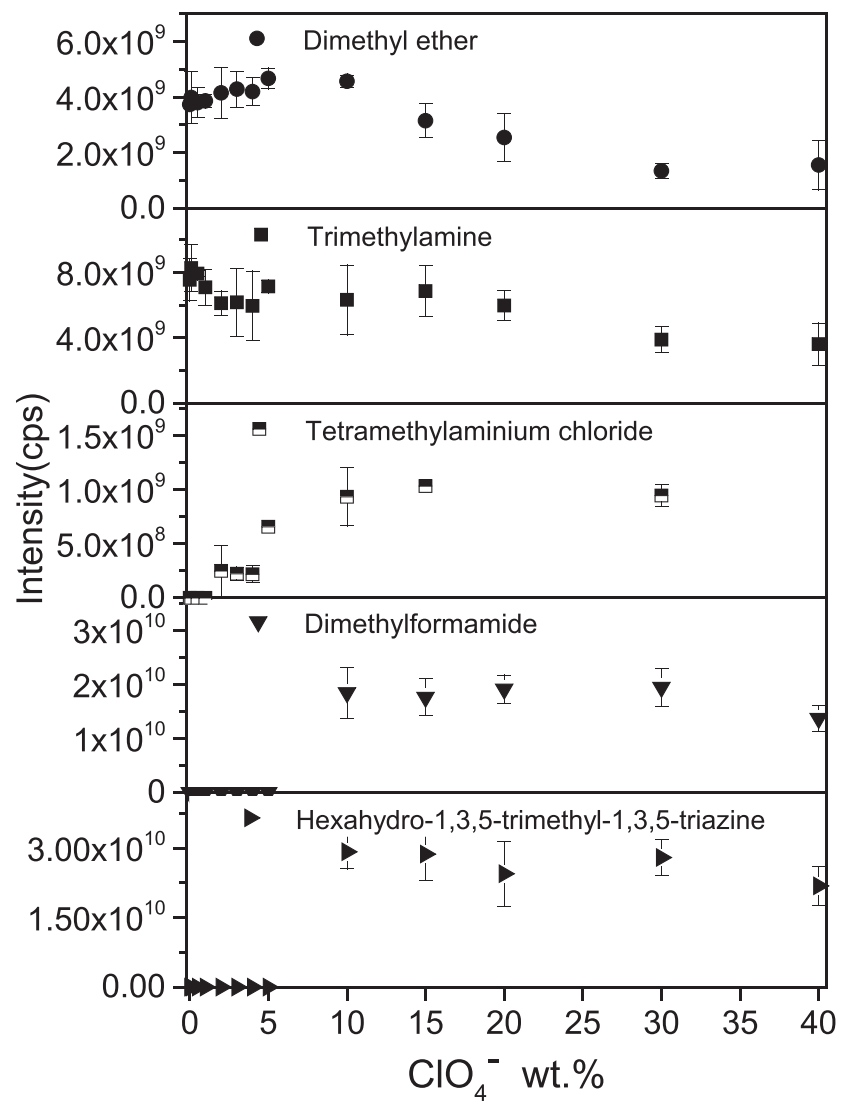

FIG. 9. The effect of $\mathrm{Ca}\left(\mathrm{ClO}_{4}\right)_{2}$ on the pyrolysis products of TMAH at a heating rate of $35^{\circ} \mathrm{C} \cdot \mathrm{min}^{-1}$ from $50^{\circ} \mathrm{C}$ to $600^{\circ} \mathrm{C}$.

ideal hydrogen bond acceptor that extends out from the rest of the molecule. The TMTAC cannot be the condensation product of nitriles because the lack of methyl groups on the nitrile $\mathrm{N}$ atom makes it impossible to form TMTAC.

To confirm the function of DMF during the formation of TMTAC, the flash pyrolysis products of DMF at $600^{\circ} \mathrm{C}$ were studied. Figure 12 shows the chromatogram of DMF flash pyrolysis at $600^{\circ} \mathrm{C}$, and the main pyrolysis products are listed in Supplementary Table S4. Results show that the TMTAC was formed during the pyrolysis of DMF at $600^{\circ} \mathrm{C}$, and $\mathrm{N}, \mathrm{N}, \mathrm{N}^{\prime}, \mathrm{N}^{\prime}$-tetramethyl-methanediamine $(\mathrm{RT}=2.77$ and $3.02 \mathrm{~min})$, dimethylamino-acetonitrile $(\mathrm{RT}=4.02 \mathrm{~min})$, and some olefins such as 1 -nonene $(\mathrm{RT}=8.53 \mathrm{~min})$ and 1 -decene (12.78 min) were detected. These results indicate that DMF is the main intermediate for the formation of these compounds.

The question remains of how DMF is formed during the TMAH pyrolysis at $600^{\circ} \mathrm{C}$ in the presence of calcium perchlorate. The thermal decomposition process of calcium perchlorate is an integral step in understanding this process. Migdał-Mikuli and Hetmańczyk (2008) studied the thermal decomposition of calcium perchlorate, which includes three main stages: the first stage is the process of dehydration as shown in reaction (2), between $184^{\circ} \mathrm{C}$ and $287^{\circ} \mathrm{C}$; the phase transition of solid to melted calcium perchlorate is the second stage according to DSC curve at $346-416^{\circ} \mathrm{C}$ as shown in reaction (3); the third stage is the decomposition of $\mathrm{Ca}\left(\mathrm{ClO}_{4}\right)_{2}$ concurrent with the formation of $\mathrm{CaCl}_{2}$ and the release of $\mathrm{O}_{2}$ at about $462^{\circ} \mathrm{C}$ [reaction (4)]. When water is

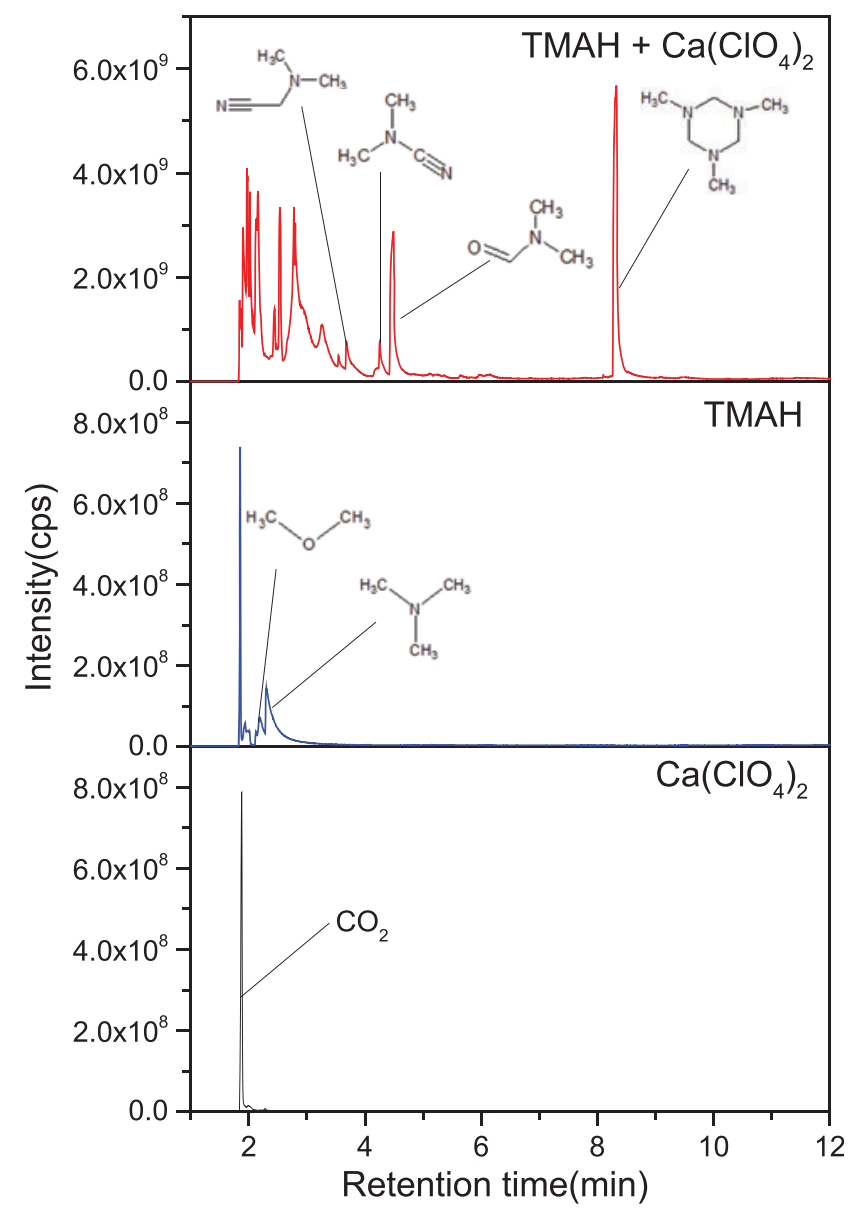

FIG. 10. The chromatography of TMAH with $20 \mathrm{wt} \%$ $\mathrm{ClO}_{4}^{-}$, TMAH, and $\mathrm{Ca}\left(\mathrm{ClO}_{4}\right)_{2}$ pyrolysis at $400-500^{\circ} \mathrm{C}$ at a heating rate of $35^{\circ} \mathrm{C} \cdot \mathrm{min}^{-1}$.

present, $\mathrm{CaCl}_{2}$ could react with $\mathrm{H}_{2} \mathrm{O}$ and release $\mathrm{HCl}$ at the pyrolysis temperatures higher than $450^{\circ} \mathrm{C}$ (Glavin et al., 2013). The oxidation of TMAH was caused by the oxygen released during the thermal decomposition of calcium perchlorate from $400^{\circ} \mathrm{C}$ to $500^{\circ} \mathrm{C}$, which can provide enough energy needed for the thermal decomposition of calcium perchlorate, as shown in Figs. 10 and 11.

$$
\begin{aligned}
{\left[\mathrm{Ca}\left(\mathrm{H}_{2} \mathrm{O}\right)_{4}\right]\left(\mathrm{ClO}_{4}\right)_{2} } & \rightarrow\left[\mathrm{Ca}\left(\mathrm{H}_{2} \mathrm{O}\right)_{2}\right]\left(\mathrm{ClO}_{4}\right)_{2}+2 \mathrm{H}_{2} \mathrm{O} \\
{\left[\mathrm{Ca}\left(\mathrm{H}_{2} \mathrm{O}\right)_{2}\right]\left(\mathrm{ClO}_{4}\right)_{2} } & \rightarrow \mathrm{Ca}\left(\mathrm{ClO}_{4}\right)_{2}+2 \mathrm{H}_{2} \mathrm{O} \mathrm{Ca}\left(\mathrm{ClO}_{4}\right)_{2} \\
& \rightarrow \mathrm{Ca}\left(\mathrm{ClO}_{4}\right)_{2}(\text { melt }) \\
\mathrm{Ca}\left(\mathrm{ClO}_{4}\right)_{2} & \rightarrow \mathrm{CaCl}_{2}+4 \mathrm{O}_{2}
\end{aligned}
$$

During the pyrolysis of TMAH, TMA was detected, which is the most likely precursor of DMF, which means that the methyl functional group of TMA or tetramethylammonium ion could be oxidized by $\mathrm{O}_{2}$ released from the degradation of calcium perchlorate. The reaction between $\mathrm{CH}_{3}$ and $\mathrm{O}_{2}$ may proceed through three different channels, as shown in reactions (5), (6), and (7) (Yu et al., 1995). 


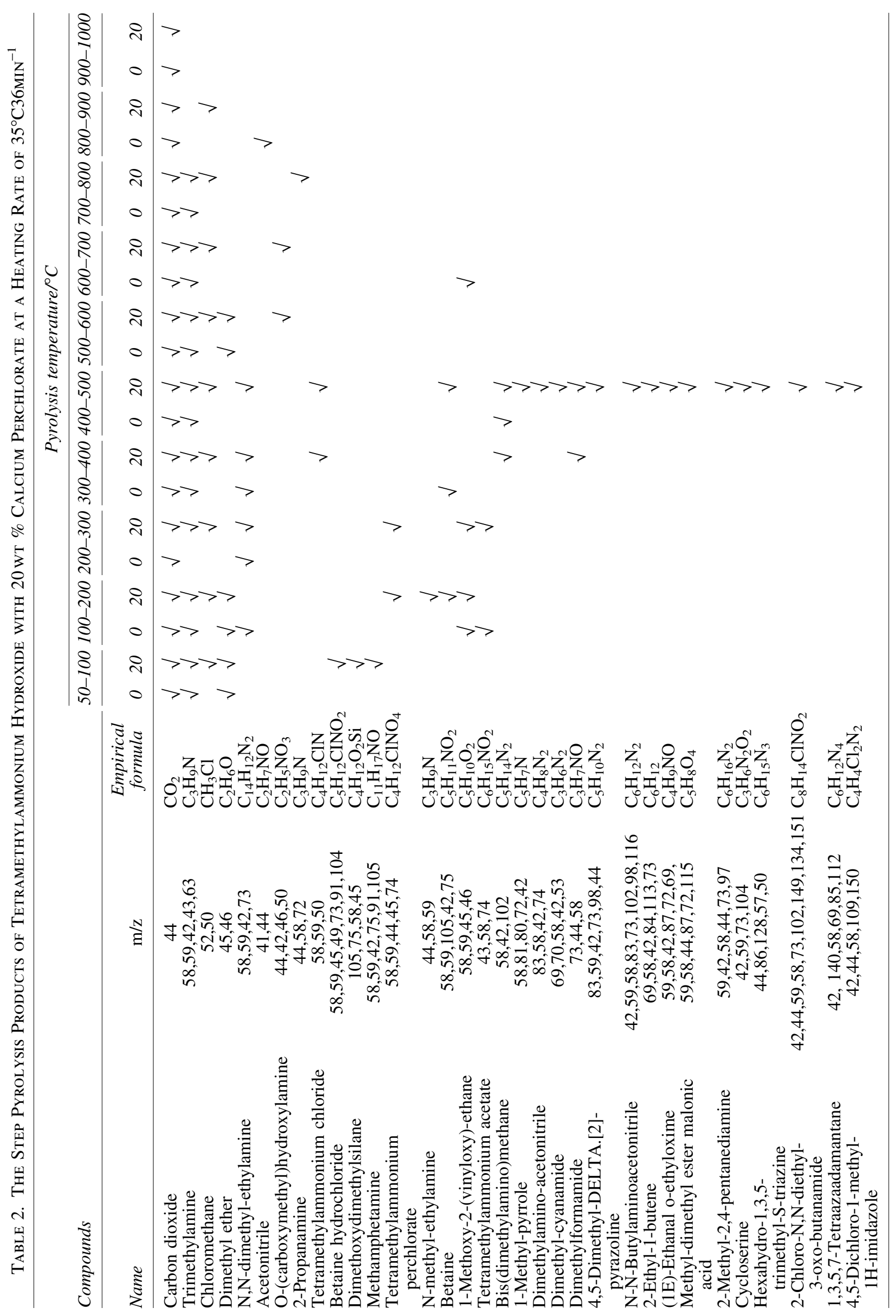




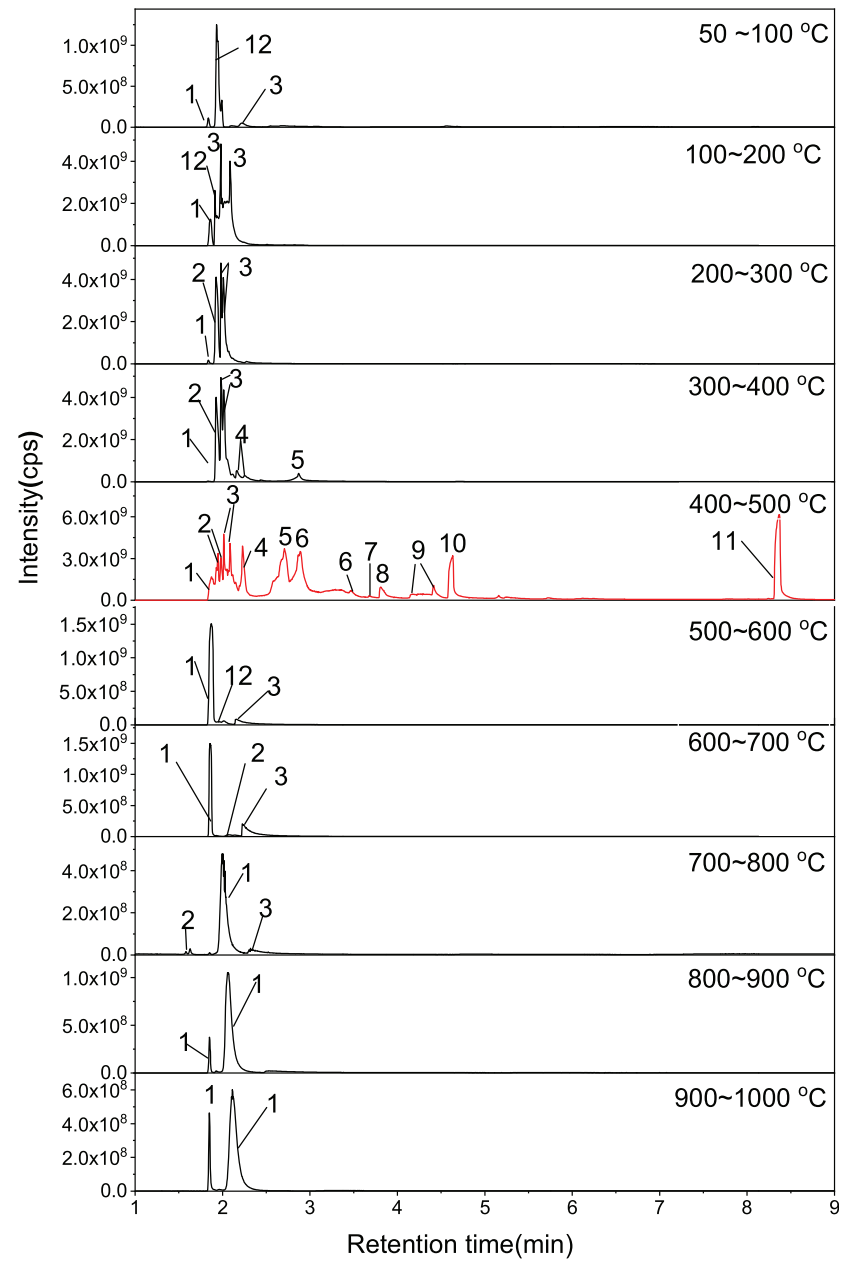

FIG. 11. Chromatograms of TMAH pyrolysis (a heating rate of $35^{\circ} \mathrm{C} \cdot \mathrm{min}^{-1}$ ) with $20 \mathrm{wt} \%$ calcium perchlorate at different temperatures. Peak 1: $\mathrm{CO}_{2}$; peak 2: Chloromethane; peak 3: TMA and isomers; peak 4: N,N-dimethyl-ethylamine; peaks 5 and 6: $\mathrm{N}, \mathrm{N}, \mathrm{N}^{\prime}, \mathrm{N}^{\prime}$-tetramethyl-methanediamine and isomers; peak 7: 1-Methyl-pyrrole; peak 8: Dimethylaminoacetonitrile; peak 9: Dimethyl-cyanamide; peak 10: N,Ndimethylformamide; peak 11: TMTAC; peak 12: Dimethyl ether.

$$
\begin{gathered}
\mathrm{CH}_{3}+\mathrm{O}_{2} \rightarrow \mathrm{CH}_{3} \mathrm{O}_{2} \\
\mathrm{CH}_{3}+\mathrm{O}_{2} \rightarrow \mathrm{CH}_{3} \mathrm{O} \cdot+\mathrm{O} . \\
\mathrm{CH}_{3}+\mathrm{O}_{2} \rightarrow \mathrm{CH}_{2} \mathrm{O}^{+}+\mathrm{OH}^{-}
\end{gathered}
$$

Reaction (5) is the main channel at low temperatures about $300 \mathrm{~K}$. Reactions (6) and (7) play a major role in the consumption of $\mathrm{CH}_{3}$ during methane oxidation at elevated temperatures. For the oxidation of TMA in this study, results showed that channel (7) is the main process of TMAH oxidation because the hydrogens are active and can be transited among different methyl groups (Vieira et al., 1984; Filley et al., 1999). Therefore, the oxidation of the methyl functional groups of the TMA or TMAH ion by oxygen released during the decomposition of calcium perchlorate is the main source of DMF formation. However, oxygen has consistently been present such that the formation of the

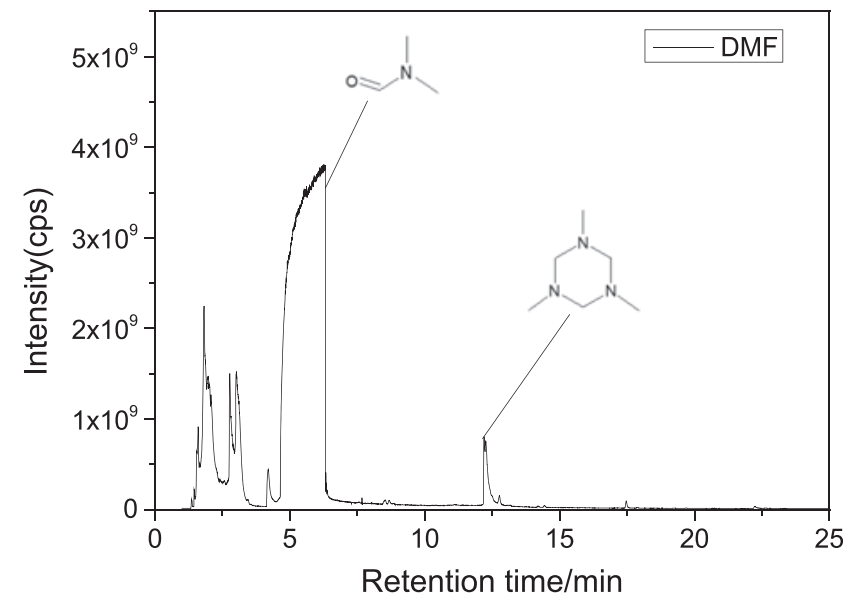

FIG. 12. The chromatography of DMF flash pyrolysis at $600^{\circ} \mathrm{C}$. DMF, N,N-dimethylformamide.

intermediate $\left(\mathrm{CH}_{3}\right)_{2} \mathrm{NCH}_{2} \mathrm{O}_{2}$ was not rate determining (Onel et al., 2013). Therefore, the formation of DMF with different percentages of calcium perchlorate did not substantially change with the $35^{\circ} \mathrm{C} \cdot \mathrm{min}^{-1}$ heating rate.

However, the potential energy surface of $\mathrm{OH}$ formation is pressure dependent (Onel et al., 2013). The pressure of TMAH flash pyrolysis increases immediately when the sample is injected into the pyrolysis chamber. At the same time, many radical fragments are formed and volatile volumes increase to facilitate the combination among these radicals and form different chemical products. Therefore, the yield of DMF during the flash pyrolysis increased with the increasing amount of calcium perchlorate, and there are many more by-products of TMAH with the SAM-like ramp pyrolysis. For the same reason, the formation of TMTAC showed a relatively stable trend with SAM-like ramp pyrolysis. Additionally, TMTAC increased with an increase of calcium perchlorate, which could also be facilitated by the higher formation and mass transfer rate of hydrogen radicals during the flash pyrolysis.

The cyanamide and acetonitrile feature a nitrogen atom $\left(\mathrm{sp}^{3}\right.$ or $\left.\mathrm{sp}^{2}\right)$ bearing a nitrile group and possess unique properties as building blocks for organic synthesis owing to their original unique structures (Larraufie et al., 2012). Cyanamide- and acetonitrile-bearing compounds are formed during TMAH pyrolysis at $600^{\circ} \mathrm{C}$ with the presence of calcium perchlorate. Examples of these products include dimethylamino-acetonitrile ( $\mathrm{RT}=5.26 \mathrm{~min}$, Fig. 5) and dimethyl-cyanamide ( $R T=5.80 \mathrm{~min}$, Fig. 5), which indicates not only oxidation but also cyanations occur during the TMAH pyrolysis with calcium perchlorate. The simplest form of cyanamide can be formed naturally.

Cyanamide is also considered as an important molecule in prebiotic chemistry with the condensation of cyanamide with $\alpha$-hydroxy aldehydes being a possible prebiotic route to cytosine-type nucleosides (Anastasi et al., 2006). Cyanamide can be formed through several different methods, including the alkylation and acylation of cyanamides, the cyanation of amines and their derivatives, and dehydration of urea and amide oximes (Nekrasov, 2004). Doubly labeled nitrile compounds have been synthesized by combining the source of $-\mathrm{CN}$ from DMF $\left(96 \%{ }^{13} \mathrm{C}\right.$ source) and ammonia 


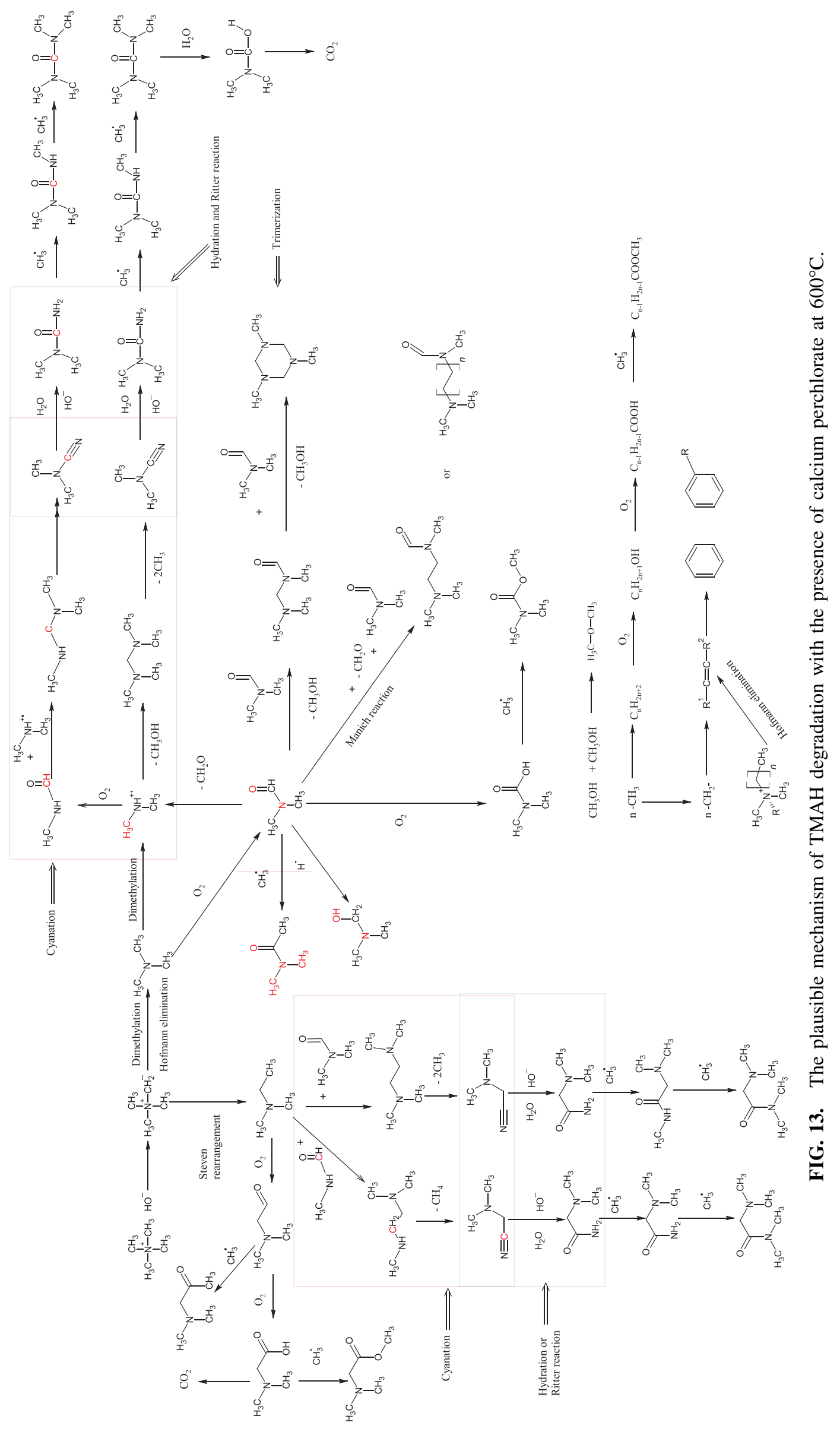


$\left(98 \%{ }^{15} \mathrm{~N}\right.$ source) in the palladium-catalyzed cyanation of aryl C-H bonds (Kim and Chang, 2010). Cyanamide can also be formed by the direct transformation of DMF (Ding and Jiao, 2011). The elements $\mathrm{N}$ and $\mathrm{C}$ in the cyano functional group derive from DMF $\left(\mathrm{C}_{3} \mathrm{H}_{7} \mathrm{NO}\right)$, whereas $\mathrm{O}_{2}$ and $-\mathrm{CH}_{3}$ are the sources of the elements $\mathrm{O}$ and $\mathrm{C}$ in the generated - $\mathrm{CHO}$ group; in other words, the functional group $-\mathrm{CHO}$ is generated from methyl oxidation by $\mathrm{O}_{2}$. Results showed that the presence of $\mathrm{H}_{2} \mathrm{O}$ decreases the yield of $-\mathrm{CN}$ formation, which could be caused by the $-\mathrm{CN}$ group hydration to amine (Camino et al., 1983).

The formation of various intermediates could also be formed through the Ritter reaction (Guérinot et al., 2012; Yin et al., 2019). Therefore, hydration processes could occur during TMAH degradation. As shown in Fig. 10, some urea-related products are formed, such as urea and $\mathrm{N}, \mathrm{N}$ dimethyl urea. Therefore, DMF is the key intermediate for the formation of cyanamide and (dimethylamino)acetonitrile during the TMAH pyrolysis in the presence of calcium perchlorate higher than $10 \mathrm{wt} \%$. This is demonstrated by the pyrolysis of DMF at $600^{\circ} \mathrm{C}$. Therefore, the formation of cyanamide and nitriles, $\mathrm{CO}_{2}$, and other by-products related to DMF formation is influenced by the formation rate of DMF; hence, these compounds' formation remains stable. The reaction route can be seen in Fig. 13.

There are two competitive processes involved: the oxidation by $\mathrm{O}_{2}$ and hydrogenation reduction by hydrogen radicals including $\cdot \mathrm{H}$ radicals and $\cdot \mathrm{CH}_{3}$ radicals formed from the demethylation reactions of TMAH. The nitrogen ylide could be oxidized to acyl-containing compounds and then further oxidized to carboxyl by $\mathrm{O}_{2}$, followed by the methylation process, or by the formation of $\mathrm{CO}_{2}$ through carboxyl elimination; and the intermediate products could be stabilized by hydrogen radicals. $\mathrm{CO}_{2}$ could also result from the partial hydrolysis of secondary and tertiary amide groups formed in branching and cross-linking reactions (Camino et al., 1983). Alternatively, the methyl groups could form the alkyl chain products via the free radical polymerization mechanism (Matheson et al., 1951).
At the same time, the aromatization of these active free radicals could occur according to the aromatization mechanism (He et al., 2019b). The cyclization reaction also plays a key role during the degradation of TMAH at $600^{\circ} \mathrm{C}$, such as the formation of pyrrole compounds that may be formed through the reaction of amine functional groups with $\alpha$-hydrogen (Choi and Ko, 2011). However, no researchers have reported the direct formation of $-\mathrm{CN}$ from TMAH pyrolysis, which would represent a new pathway for cyanamide and nitrile formation. However, the hydroxyl ion can catalyze the hydrolysis of cyanamide, which could be decomposed in alkaline solutions to urea (Hetherington and Braham, 1923) as well as polymerized to dicyanodiamide.

As mentioned before, the decomposition of TMAH at low temperatures $\left(\mathrm{ca} .200^{\circ} \mathrm{C}\right)$ has two possible pathways: the $\mathrm{S}_{\mathrm{N}} 2$ and the ylide pathway. Based on the TMAH pyrolysis products at $600^{\circ} \mathrm{C}$, the nucleophilic attack of TMAH and the ylide intermediate pathway is a more satisfactory explanation. Ylide is another important compound for the formation of nitrogen-containing by-products, including dimethylmethanolamine, dimethylamine, and $\mathrm{N}, \mathrm{N}, \mathrm{N}^{\prime}, \mathrm{N}^{\prime}$-tetramethylmethanediamine (Camino et al., 1983), all formed during the TMAH pyrolysis process. For example, unstable ylides can decompose to produce dimethyl ethylamine and polyethylene, and the ylide would be involved in the formation of the dimethyl ether (Wittig and Polster, 1956). The ylide can rearrange via intramolecular hydrogen exchange to form the dimethyl ether products mixed with $\mathrm{CH}_{3} \mathrm{OCH}_{3}$, $\mathrm{CH}_{2}$-DOCHs, $\mathrm{CHD}_{2} \mathrm{OCH}_{3}$, and $\mathrm{CD}_{3} \mathrm{OCH}_{3}$ (Musker and Stevens, 1968; Kenig et al., 2016). The charge distribution of N-containing ylides is largely affected by the electronwithdrawing properties of the quaternary nitrogen (Tsuchiya and Seno, 1979). Other than the Mannich reaction (Arend et al., 1998; Marques, 2006), in situ dehydration of water from the hemiaminal products of the reaction between formaldehyde-containing compounds and an amine also plays an important role in the formation of different alkyl ylides, as shown in Fig. 13.
FIG. 14. The effect of calcium perchlorate on the recovery of fatty acids by TMAH thermochemolysis.

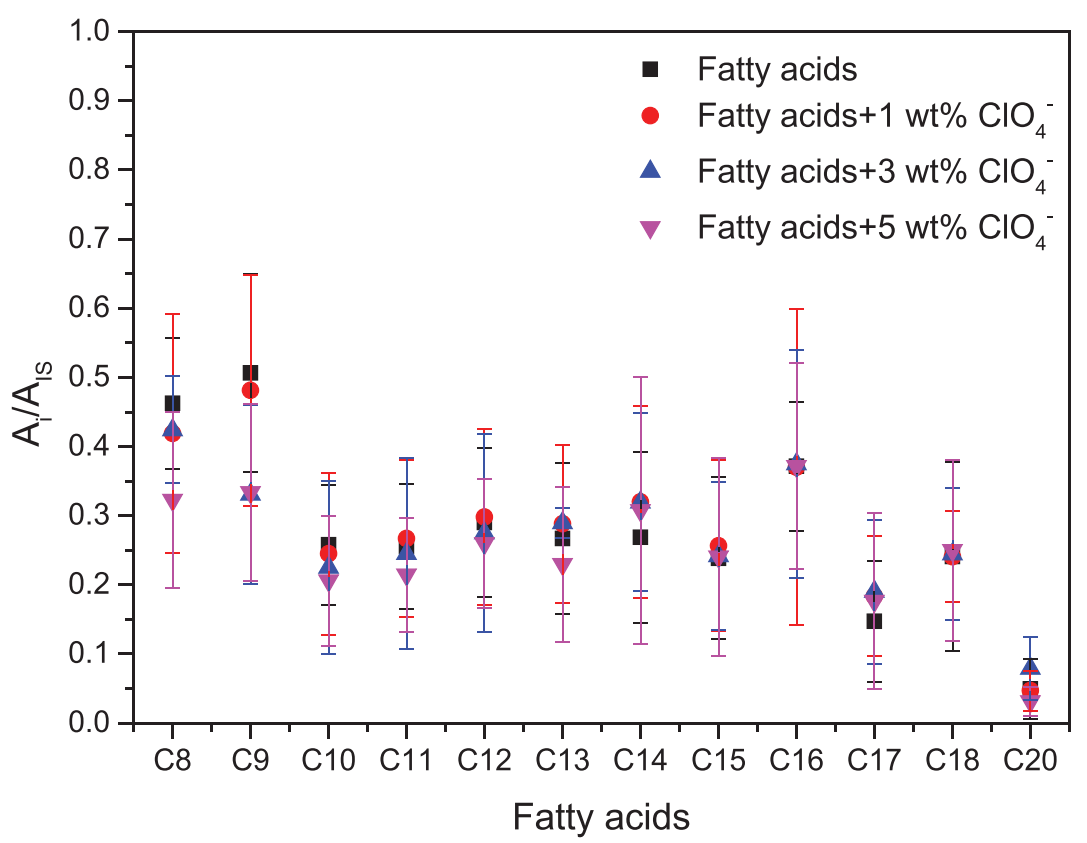




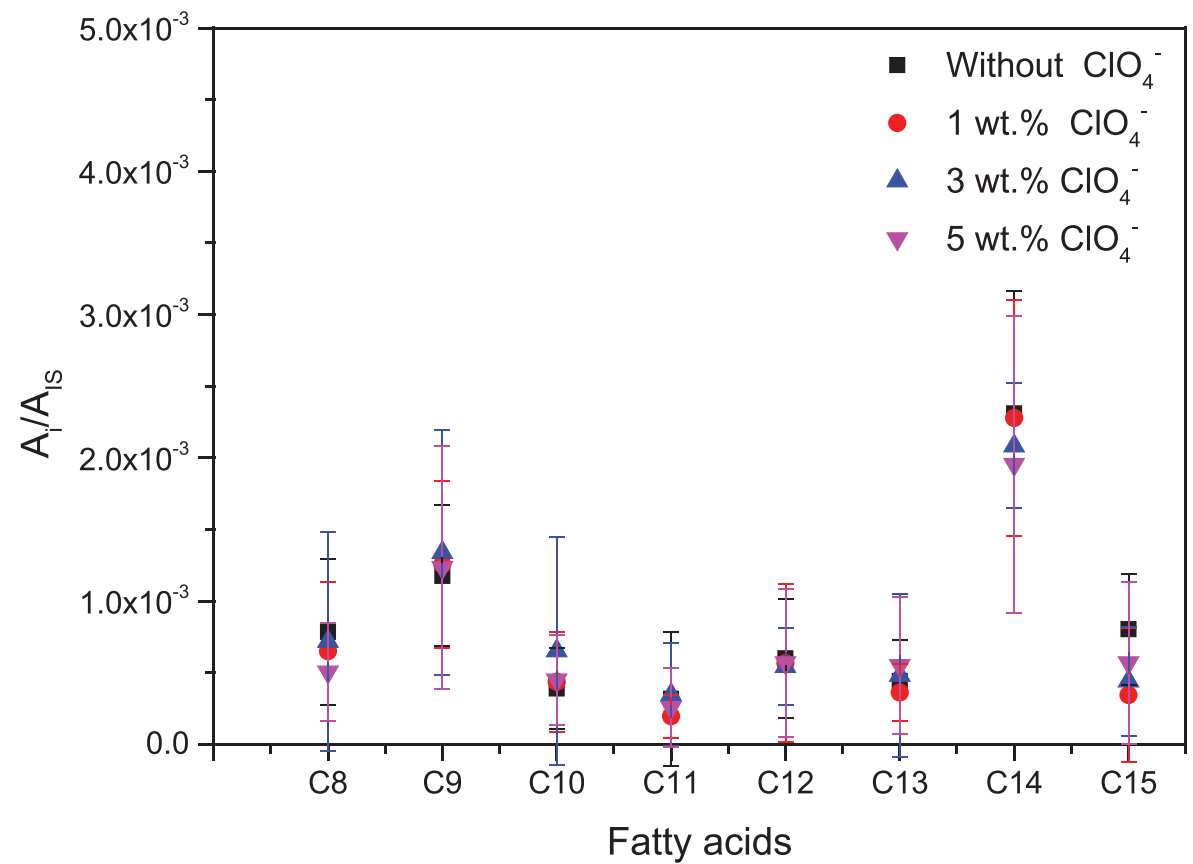

FIG. 15. The recovery of fatty acids with TMAH thermochemolysis on Mars-like conditions. The concentration of perchlorate is the ratio of perchlorate to organics (300 ppb of fatty acids).

\subsection{Fatty acid recovery with TMAH thermochemolysis in the presence of calcium perchlorate}

Finally, the performance of TMAH on the recovery of fatty acids ( $16 \mathrm{nmol}$ ) was studied. Although there are several new products formed during the pyrolysis of TMAH with higher than $10 \mathrm{wt} \%$ calcium perchlorate, the highest concentration of $\mathrm{ClO}_{4}^{-}$detected on Mars is $\sim 1 \mathrm{wt} \%$ (Archer et al., 2016; Sutter et al., 2017b). Therefore, the effect of calcium perchlorate (lower than $5 \mathrm{wt} \%$ ) on the detection of fatty acids was studied. Naphthalene-d8 was used as the internal standard, and the fatty acids were quantified by rationing the peak area of the fatty acid divided by the peak area of naphthalene-d8. Figure 14 shows the recovery of fatty acids without and with different percentages of calcium perchlorate. Results demonstrate that the increase in calcium perchlorate up to $5 \mathrm{wt} \%$ has nearly no effect on the detection of fatty acids. Additionally, the concentration of the methyl group (about $86 \mu \mathrm{mol}$, calculation is shown in the Supplementary Data) used to derivatize the fatty acids is much greater than (in excess) the concentration needed to complete fatty acid methylation (of $16 \mathrm{nmol}$, calculation is shown in the Supplementary Data). Therefore, the calcium perchlorate has no obvious effect on the recovery of the fatty acids.

To further explore how calcium perchlorate may affect the detection of organics on Mars, experiments were conducted that utilized the same concentration of fatty acids and perchlorate as has been reported from Mars (Guzman et al., 2018). Chlorobenzene has been detected on Mars at $300 \mathrm{ppb}$ and is used as a proxy for the concentration of organics on Mars for this experiment. Perchlorate on Mars has been detected at about 1\% (Ming et al., 2014). The Curiosity rover that carries the SAM instrument is capable of delivering $c a$. $20 \mathrm{mg}$ of sample to SAM for a TMAH thermochemolysis experiment. Therefore, $c a .6 \times 10^{-9} \mathrm{~g}(300 \mathrm{ppb} \times 20 \mathrm{mg}=6 \times$ $\left.10^{-9} \mathrm{~g}\right)$ of fatty acids and $0.2 \mathrm{mg}(1 \% \times 20 \mathrm{mg}) \mathrm{ClO}_{4}^{-}$were set to simulate the Mars conditions for this experiment.
Figure 15 shows the recovery of fatty acids with and without calcium perchlorate on Mars-like conditions. Different percentages of calcium perchlorate have nearly no effect on the detection of fatty acids at these ratios. The calcium perchlorate used in this study can release $4 \times 10^{-6}$ mol of $\mathrm{O}_{2}$, the abundance of TMAH is about 4.4 times higher than the amount of $\mathrm{O}_{2}$, and the $\mathrm{C}$ abundance is 17.6 times higher than that of $\mathrm{O}_{2}$ (calculation is shown in the Supplementary Data). However, TMAH can be degraded to methyl radicals, which more readily react with $\mathrm{O}_{2}$. The fatty acids used in these experiments are very stable (Rustan and Drevon, 2001) and have been derivatized to methyl esters by TMAH thermochemolysis, the methylation of the groups containing esters and ethers could increase the thermodynamic stability and chromatographic detection by GC-MS (Tadini et al., 2015). However, methyl groups can be formed when TMAH pyrolysis temperatures reach to $100^{\circ} \mathrm{C}$, readily driving forward reactions with $\mathrm{O}$ radicals (Lee and Bozzelli, 2003). The presence of calcium perchlorate did not show obvious effects on fatty acid recovery (about 11.8 pmol, calculation is shown in the Supplementary Data). Hence, the excess TMAH to sample ratio is essential for the detection of organics with the SAM and MOMA instruments. However, long-alkyl chains in fatty acids tend to make their detection more difficult.

\section{Conclusions}

In this study, the degradation of TMAH with and without the presence of calcium perchlorate at flash pyrolysis and SAM-like ramp pyrolysis to $600^{\circ} \mathrm{C}$ was studied. Some chloride-related compounds were detected during TMAH pyrolysis with higher than $10 \mathrm{wt} \%$ calcium perchlorate, including chloromethane, tetramethylammonium chloride, 5-chloro-2-pyridinol, 5-chloro-1-methylimidazole, and 4,5dichloro-1-methyl-imidazole. Although the peak intensity of these chlorinated compounds was more than 1000 times lower than that of the main products, they are the potential 
candidates for the chloride-containing by-products of TMAH. Therefore, TMAH showed little reactivity with chlorine-containing substances.

We also conclude that calcium perchlorate does not affect TMAH degradation at an SAM-like ramp pyrolysis temperature of $600^{\circ} \mathrm{C}$ when calcium perchlorate concentrations are lower than $10 \mathrm{wt} \%$. Although TMA and dimethyl ether are the main by-products of TMAH pyrolysis, some new by-products are formed when the calcium perchlorate concentrations is higher than $10 \mathrm{wt} \%$. DMF is formed because of methyl group oxidation by $\mathrm{O}_{2}$ released from the decomposition of calcium perchlorate and followed by the formation of cyanamide and acetonitrile through the cyanation route of amines. TMTAC is formed by the trimerization of DMF, which is a crucial intermediate for the formation of other nitrogen-containing byproducts of TMAH. Urea is formed through the Ritter reaction and the Mannich reaction, and the Steven rearrangement and the Hofmann elimination are involved in the formation of various intermediates and ylides. However, in our experimental conditions, calcium perchlorate did not affect the recovery of fatty acids with TMAH thermochemolysis, even when the fatty acid volume was low. These lines of evidence demonstrate that TMAH is a good thermochemolysis reagent at high temperature $\left(600^{\circ} \mathrm{C}\right)$ for the methylation and detection of organics on Mars with the SAM and MOMA instruments.

\section{Acknowledgments}

We thank three anonymous reviewers for critically reviewing this article, thanks for their constructive comments and suggestions, and we also thank Sherry L. Cady for her editorial work.

\section{Author Disclosure Statement}

No competing financial interests exist.

\section{Funding Information}

The authors are grateful for the support of the French Space Agency (Centre National d'Etudes Spatiales) and SAM/ MOMA funding, and the CSC scholarship (201701810036). R.N.-G. has received funds from the Universidad Nacional Autónoma de México (PAPIIT IN111619).

\section{Supplementary Material}

Supplementary Table S1

Supplementary Table S2

Supplementary Table S3

Supplementary Table S4

Supplementary Data

\section{References}

Anastasi C, Crowe MA, Powner MW, et al. (2006) Direct assembly of nucleoside precursors from two- and three-carbon units. Angew Chemie Int Ed 45:6176-6179.

Archer PD, Ming DW, Sutter B, et al. (2016) Oxychlorine species on Mars: implications from Gale Crater samples [abstract 2947]. In 47th Lunar and Planetary Science Conference, Lunar and Planetary Institute, Houston, TX.

Arend M, Westermann B, and Risch N (1998) Modern variants of Mannich-reaction. Angew Chem Int Ed 37:1044-1070.
Attri P, Venkatesu P, and Kumar A (2010) Temperature effect on the molecular interactions between ammonium ionic liquids and N, N-dimethylformamide. J Phys Chem B 114: 13415-13425.

Bridgwater AV and Peacocke GVC (2000) Fast pyrolysis processes for biomass. Renew Sustain Energy Rev 4:1-73.

Bruck AM, Sutter B, Ming DW, et al. (2014) Thermal decomposition of calcium perchlorate/iron-mineral mixtures: implication of the evolved oxygen from the Rocknest eolian deposit Gale Crater, Mars [abstract 2057]. In 45th Lunar and Planetary Science Conference, Lunar and Planetary Institute, Houston.

Bryan P and Bhaskara P (1976) Comparison of standards in the Karl Fischer method for water determination. Anal Chim Acta 84:149-155.

Buch A, Belmahdi I, Szopa C, et al. (2019) Role of the Tenax ${ }^{\circledR}$ adsorbent in the interpretation of the EGA and GC-MS analyses performed with the sample analysis at Mars in Gale Crater. J Geophys Res Planets 124:2819-2851.

Burns EA and Muraca RF (1962) Karl Fischer determination of water in ammonium perchlorate with automatic titration apparatus: evaluation of reaction rate parameters and statistical evaluation. Anal Chem 34:848-854.

Camino G, Operti L, and Trossarelli L (1983) Mechanism of thermal degradation of urea-formaldehyde polycondensates. Polym Degrad Stab 5:161-172.

Cannon KM, Sutter B, Ming DW, et al. (2012) Perchlorate induced low temperature carbonate decomposition in the Mars Phoenix Thermal and Evolved Gas Analyzer (TEGA). Geophys Res Lett 39:2-6.

Chempath S, Einsla BR, Pratt LR, et al. (2008) Mechanism of tetraalkylammonium headgroup degradation in alkaline fuel cell membranes. J Phys Chem C 112:3179-3182.

Chempath S, Boncella JM, Pratt LR, et al. (2010) Density functional theory study of degradation of tetraalkylammonium hydroxides. J Phys Chem C 14:11977-11983.

Choi S-S and Ko J (2011) Analysis of cyclic pyrolysis products formed from amino acid monomer. J Chromatogr A 1218: 8443-8455.

Ding S and Jiao N (2011) Direct transformation of N,Ndimethylformamide to -CN: Pd-catalyzed cyanation od heteroarenes via $\mathrm{C}-\mathrm{H}$ functionalization. J Am Chem Soc 133: 12374-12377.

Edson JB, Macomber CS, Pivovar BS, et al. (2012) Hydroxide based decomposition pathways of alkyltrimethylammonium cations. J Membr Sci 399-400:49-59.

Eigenbrode JL, Summons RE, Steele A, et al. (2018) Organic matter preserved in 3-billion-year-old mudstones at Gale Crater, Mars. Science 360:1096-1101.

Ewa W and Piotr S (2009) Water determination in bee products using the Karl Fisher titration method. J Apic Sci 53:49-56.

Farley KA, Martin P, Archer PD, et al. (2016) Light and variable ${ }^{37} \mathrm{Cl} /{ }^{35} \mathrm{Cl}$ ratios in rocks from Gale Crater, Mars: possible signature of perchlorate. Earth Planet Sci Lett 438:14-24.

Fayiga AO and Ma LQ (2006) Using phosphate rock to immobilize metals in soil and increase arsenic uptake by hyperaccumulator Pteris vittata. Sci Total Environ 359:17-25.

Filley TR, Minard RD, and Hatcher PG (1999) Tetramethylammonium hydroxide (TMAH) thermochemolysis: proposed mechanisms based upon the application of ${ }^{13} \mathrm{C}$ labeled TMAH to a synthetic model lignin dimer. Org Geochem 30:607-621.

Freissinet C, Glavin DP, Mahaffy PR, et al. (2015) Organic molecules in the Sheepbed Mudstone, Gale Crater, Mars. J Geophys Res Planets 120:495-514. 
Galletti GC and Piccaglia R (1988) Water determination in silages by Karl Fischer titration. J Sci Food Agric 43:1-7.

Glavin DP, Freissinet C, Miller KE, et al. (2013) Evidence for perchlorates and the origin of chlorinated hydrocarbons detected by SAM at the Rocknest aeolian deposit in Gale Crater. J Geophys Res Planets 118:1955-1973.

Goesmann F, Brinckerhoff WB, Raulin F, et al. (2017) The Mars Organic Molecule Analyzer (MOMA) instrument: characterization of organic material in martian sediments. Astrobiology 17:655-685.

Guérinot A, Reymond S, and Cossy J (2012) Ritter reaction: recent catalytic developments. European J Org Chem 2012: 19-28.

Guzman M, McKay CP, Quinn RC, et al. (2018) Identification of chlorobenzene in the Viking gas chromatograph-mass spectrometer data sets: reanalysis of Viking mission data consistent with aromatic organic compounds on Mars. J Geophys Res Planets 123:1674-1683.

He W, Liu Z, Liu Q, et al. (2014) Behaviors of radical fragments in tar generated from pyrolysis of 4 coals. Fuel 134: 375-380.

He Y, Buch A, Morisson M, et al. (2019a) Application of TMAH thermochemolysis to the detection of nucleobases: application to the MOMA and SAM space experiment. Talanta 204:802-811.

He Y, Yan L, Liu Y, et al. (2019b) Effect of $\mathrm{SiO}_{2} / \mathrm{Al}_{2} \mathrm{O}_{3}$ ratios of HZSM-5 zeolites on the formation of light aromatics during lignite pyrolysis. Fuel Process Technol 188:70-78.

He Y, Buch A, Szopa C, et al. (2020) The search for organic compounds with TMAH thermochemolysis: from Earth analyses to space exploration experiments. Trends Anal Chem 127:115896.

Hecht MH, Kounaves SP, Quinn RC, et al. (2009) Detection of perchlorate and the soluble chemistry of martian soil at the Phoenix lander site. Science 325:64-67.

Hetherington HC and Braham JM (1923) The hydrolysis and polymerization of cyanamide. J Am Chem Soc 45:824-829.

Hogancamp JV, Sutter B, Morris RV, et al. (2018) Chlorate/Febearing phase mixtures as a possible source of oxygen and chlorine detected by the sample analysis at mars instrument in Gale Crater, Mars. J Geophys Res Planets 123:2920-2938.

Kenig F, Chou L, McKay CP, et al. (2016) Perchlorate and volatiles of the brine of Lake Vida (Antarctica): implication for the in situ analysis of Mars sediments. J Geophys Res Planets 121:1190-1203.

Kim J and Chang S (2010) A new combined source of "CN" from N,N-dimethylformamide and ammonia in the palladium-catalyzed cyanation of aryl C-H bonds. J Am Chem Soc 132:10272-10274.

Kounaves SP, Carrier BL, O'Neil GD, et al. (2014a) Evidence of martian perchlorate, chlorate, and nitrate in Mars meteorite EETA79001: implications for oxidants and organics. Icarus 229:206-213.

Kounaves SP, Chaniotakis NA, Chevrier VF, et al. (2014b) Identification of the perchlorate parent salts at the Phoenix Mars landing site and possible implications. Icarus 232:226-231.

Larraufie MH, Maestri G, Malacria M, et al. (2012) The cyanamide moiety, synthesis and reactivity. Synthesis (Stuttg) 44:1279-1292.

Lawson AT and Collie N (1888) The action of heat on the salts of tetramethylammonium. J Chem Soc Trans 53:624-636.

Lee J and Bozzelli JW (2003) Thermochemical and kinetic analysis of the formyl methyl radical $+\mathrm{O}_{2}$ reaction system. $J$ Phys Chem A 107:3778-3791.
Leshin LA, Mahaffy PR, Webster CR, et al. (2013) Volatile, isotope, and organic analysis of martian fines with the Mars Curiosity rover. Science 341:1238937.

Long $\mathrm{H}$ and Pivovar BS (2012) Hydroxide degradation pathways for substituted benzyltrimethyl ammonium: a DFT study. J Phys Chem C 116:9419-9426.

Macomber CS, Boncella JM, Pivovar BS, et al. (2008) Decomposition pathways of an alkaline fuel cell membrane material component via evolved gas analysis. $J$ Therm Anal Calorim 93:225-229.

Mahaffy PR, Webster CR, Cabane M, et al. (2012) The Sample Analysis at Mars investigation and instrument suite. Space Sci Rev 170:401-478.

Marques MMB (2006) Catalytic enantioselective cross-Mannich reaction of aldehydes. Angew Chem Int Ed 45:348-352.

Marvin GG and Woolaver LB (1945) Thermal decomposition of perchlorates. Ind Eng Chem Anal Ed 17:474-476.

Matheson MS, Auer EE, Bevilacqua EB, et al. (1951) Rate constants in free radical polymerizations. IV. Methyl acrylate. $J$ Am Chem Soc 73:5395-5400.

Migdał-Mikuli A and Hetmańczyk J (2008) Thermal behavior of $\left[\mathrm{Ca}\left(\mathrm{H}_{2} \mathrm{O}\right)_{4}\right]\left(\mathrm{ClO}_{4}\right)_{2}$ and $\left[\mathrm{Ca}\left(\mathrm{NH}_{3}\right)_{6}\right]\left(\mathrm{ClO}_{4}\right)_{2}$. J Therm Anal Calorim 91:529-534.

Milačič R, Štupar J, Kožuh N, et al. (1992) Critical evaluation of three analytical techniques for the determination of chromium(VI) in soil extracts. Analyst 117:125-130.

Millan M, Szopa C, Buch A, et al. (2019) Performance of the SAM gas chromatographic columns under simulated flight operating conditions for the analysis of chlorohydrocarbons on Mars. J Chromatogr A 1598:183-195.

Miller KE, Kotrc B, Summons RE, et al. (2015) Evaluation of the Tenax trap in the Sample Analysis at Mars instrument suite on the Curiosity Rover as a potential hydrocarbon source for chlorinated organics detected in Gale Crater. $J$ Geophys Res Planets 120:1446-1459.

Ming DW, Archer PD, Jr., Glavin DP, et al. (2014) Volatile and organic compositions of sedimentary rocks in Yellowknife Bay, Gale Crater, Mars. Science 343:1245267.

Montgomery W, Jaramillo EA, Royle SH, et al. (2019) Effects of oxygen-containing salts on the detection of organic biomarkers on Mars and in terrestrial analog soils. Astrobiology 19:711-721.

Morisson M, Buch A, Szopa C, et al. (2017) TMAH thermochemolysis of a martian regolith simulant: optimization of an analytical method for the detection of trace organic matter by the MOMA-Pyr-GC-MS experiment onboard the ExoMars2020 rover [abstract 1079]. In 48th Lunar and Planetary Science Conference, Lunar and Planetary Institute, Houston. Musker WK (1964) A reinvestigation of the pyrolysis of tetramethylammonium hydroxide. J Am Chem Soc 86:960-961.

Musker WK (1967) Nitrogen yields. III. Explosive decomposition of tetramethylammonium amide. J Org Chem 32:31893191.

Musker WK and Stevens RR (1968) Nitrogen ylides. IV. The role of the methyl hydrogen atoms in the decomposition of tetramethylammonium alkoxides. J Am Chem Soc 90:3515-3521.

Nekrasov DD (2004) Synthesis and chemical transformations of mono- and disubstituted cyanamides. Russ J Org Chem 40: 1439-1454.

Ogata Y and Kawasaki A (1964) The kinetics of the reaction of formaldehyde with ammonia. Bull Chem Soc Jpn 37:514519.

Onay O and Mete Kockar O (2003) Slow, fast and flash pyrolysis of rapeseed. Renew Energy 28:2417-2433. 
Onel L, Thonger L, Blitz MA, et al. (2013) Gas-phase reactions of $\mathrm{OH}$ with methyl amines in the presence or absence of molecular oxygen. an experimental and theoretical study. $J$ Phys Chem A 117:10736-10745.

Rustan AC and Drevon CA (2005) Fatty acids: structures and properties. In L. John Wiley \& Sons (Ed.), Encycl Life Sci 1-7.

Seaman WM, McComas WH, and Allen GA (1949) Determination of water by Karl Fischer reagent. Anal Chem 21:510-512.

Sephton MA, Lewis JMT, Watson JS, et al. (2014) Perchlorateinduced combustion of organic matter with variable molecular weights: implications for Mars missions. Geophys Res Lett 41:7453-7460.

Špirić Z, Vučković I, Stafilov T, et al. (2013) Air pollution study in Croatia using moss biomonitoring and ICP-AES and AAS analytical techniques. Arch Environ Contam Toxicol 65: 33-46.

Steininger H, Goesmann F, and Goetz W (2012) Influence of magnesium perchlorate on the pyrolysis of organic compounds in Mars analogue soils. Planet Space Sci 71:9-17.

Subramanian V (2009) 1,3,5-Trimethyl-1,3,5-triazacyclohexane. In L. John Wiley \& Sons (Ed.), Encyclopedia of Reagents for Organic Synthesis. pp. 1-2.

Supsana P, Liaskopoulos T, Tsoungas PG, et al. (2007) DMFcatalysed thermal dehydration of aldoximes: a convenient access to functionalized aliphatic and aromatic nitriles. Synlett 2671-2674.

Surpateanu A, Catteau G, Karafiloglou JP, et al. (1976) Structure and reactivity of cycloimmonium ylides. Tetrahedron 32: 2647-2663.

Sutter B, Quinn RC, Archer PD, et al. (2017a) Measurements of oxychlorine species on Mars. Int J Astrobiol 16:203-217.

Sutter B, McAdam AC, Mahaffy PR, et al. (2017b) Evolved gas analyses of sedimentary rocks and eolian sediment in Gale Crater, Mars: results of the Curiosity rover's sample analysis at Mars instrument from Yellowknife Bay to the Namib Dune. J Geophys Res Planets 122:2574-2609.

Tadini AM, Pantano G, de Toffoli AL, et al. (2015) Off-line TMAH-GC/MS and NMR characterization of humic substances extracted from river sediments of northwestern São Paulo under different soil uses. Sci Total Environ 506-507:234-240.

Tsuchiya S and Seno M (1979) On the bond character of N-containing ylides. J Org Chem 44:2850-2855.

Vieira KL, Mubarak MS, and Peters DG (1984) Use of deuterium labeling to assess the roles of tetramethylammonium cation, dimethylformamide, and water as proton donors for electrogenerated tert-butyl carbanions. Evidence for the formation of an ylide (trimethylammonium methylide). $J \mathrm{Am}$ Chem Soc 106:5372-5373.

Wang CW and Liang C (2014) Oxidative degradation of TMAH solution with UV persulfate activation. Chem Eng J 254:472-478.

Williams AJ, Eigenbrode J, Floyd M, et al. (2019) Recovery of fatty acids from mineralogic Mars analogs by TMAH thermochemolysis for the Sample Analysis at Mars wet chemistry experiment on the Curiosity Rover. Astrobiology 19:522-546.

Wittig VG and Polster R (1956) Über die Struktur der Stickstoff-ylide. Justus Liebigs Ann Chem 599:1-12.

Yin G, Yan B, Chen J, et al. (2019) An efficient transformation of methyl ethers and nitriles to amides catalyzed by iron(III) perchlorate hydrate. J Iran Chem Soc 16:1355-1363.
Yu CL, Wang C, and Frenklach M (1995) Chemical kinetics of methyl oxidation by molecular oxygen. J Phys Chem 99: 14377-14387.

Zagatto EAG, Krug FJ, Bergamin H, et al. (1979) Merging zones in flow injection analysis. Part 2. Determination of calcium, magnesium and potassium in plant material by continuous flow injection atomic absorption and flame emission spectrometry. Anal Chim Acta 104:279-284.

Zeffiro A, Lazzaroni S, Merli D, et al. (2016) Formation of hexamethylenetetramine (HMT) from $\mathrm{HCHO}$ and $\mathrm{NH}_{3}-$ relevance to prebiotic chemistry and B3LYP consideration. Orig Life Evol Biosph 46:223-231.

Zverev VG, Kuznetsov VV, Rykov AN, et al. (2007) A gas electron diffraction study of the conformational composition of 1,3,5-trimethyl-1,3,5-triazacyclohexane. Russ J Phys Chem A 81:1639-1644.

Address correspondence to: Yuanyuan $\mathrm{He}$

Laboratoire Génie des Procédés et Matériaux CentraleSupélec

University Paris-Saclay 8-10 rue Joliot-Curie Gif-sur-Yvette 91190

France

E-mail: yuanyuan.he@centralesupelec.fr

Submitted 17 February 2020

Accepted 12 October 2020 Associate Editor: Victor Parro

$\begin{aligned} & \text { Abbreviations Used } \\ & \mathrm{CaCl}_{2}=\text { calcium chloride } \\ & \mathrm{DMF}=\mathrm{N}, \mathrm{N} \text {-dimethylformamide } \\ & \mathrm{DSC}=\text { differential scanning calorimetry } \\ & \mathrm{EGA}=\text { evolved gas analysis } \\ & \mathrm{GC}-\mathrm{MS}=\text { gas chromatography-mass spectrometry } \\ & \mathrm{HCl}=\text { hydrogen chloride } \\ & \mathrm{HMT}=\text { hexamethylenetetramine } \\ & \mathrm{IS}=\text { internal standard } \\ & \mathrm{MOMA}=\text { Mars Organic Molecule Analyzer } \\ & \mathrm{MTBSTF}=\text { N-tert-Butyldimethylsilyl-N- } \\ & \text { methyltrifluoroacetamide } \\ & \text { Pyr-GC-MS }=\text { pyrolysis-gas chromatography coupled } \\ & \text { to mass spectrometry } \\ & \mathrm{RT}=\text { retention time } \\ & \mathrm{SAM}=\text { Sample Analysis at Mars } \\ & \mathrm{SSL}=\text { split/splitless } \\ & \mathrm{TG}=\text { thermal gravimetry } \\ & \mathrm{TMA}=\text { trimethylamine } \\ & \mathrm{TMAH}=\text { tetramethylammonium hydroxide } \\ & \mathrm{TMTAC}=1,3,5 \text {-trimethyl-1,3,5-triazacyclohexane } \\ & \mathrm{TS}=\text { transition state } \\ & \mathrm{VL}-2=\text { Viking Lander } 2 \\ & \mathrm{WCL}=\text { wet chemistry laboratory }\end{aligned}$

